Research Article

\title{
Microseismic Response Characteristics Induced by Mining Activities: A Case Study
}

\author{
Xuesong Bai,, ${ }^{1,2}$ Zhi Tang, ${ }^{1,2}$ Tao Zhao,, ${ }^{1,2}$ Xiaoyang Cheng $\mathbb{D}^{3,4}$ and Kai Chen ${ }^{1,2}$ \\ ${ }^{1}$ College of Safety Science and Engineering, Liaoning Technical University, Liaoning 123000, China \\ ${ }^{2}$ School of Mechanical \& Engineering, Liaoning Technical University, Liaoning 123000, China \\ ${ }^{3}$ State Key Laboratory of the Gas Disaster Detecting, Preventing and Emergency Controlling, Chongqing 400037, China \\ ${ }^{4}$ China Coal Technology and Engineering Group Chongqing Research Institute, Chongqing 400037, China \\ Correspondence should be addressed to Xiaoyang Cheng; cqmkycxyang@163.com
}

Received 24 March 2021; Revised 17 August 2021; Accepted 30 August 2021; Published 23 September 2021

Academic Editor: Faming Huang

Copyright $\odot 2021$ Xuesong Bai et al. This is an open access article distributed under the Creative Commons Attribution License, which permits unrestricted use, distribution, and reproduction in any medium, provided the original work is properly cited.

\begin{abstract}
For deep coal mines, geological disturbances or mining activities can cause damage to coal and rock masses, easily inducing dynamic disasters such as rock bursts or coal and gas outbursts, which seriously threaten the safety production of coal mine. In this paper, first, the Liyazhuang Coal Mine introduced the SOS MS (Sensor Observation Service Microseismic) monitoring system from the Polish Research Institute and verified the accuracy of its positioning. Then, to study the characteristics of MS signals induced by different mining activities, based on the field monitoring results, the waveform and frequency spectrum characteristics of MS signals at different energy levels induced by different mining activities are analyzed, and the energy levels of MS signals caused by different mining activities are classified. Studies have shown that there are large differences in the waveform and spectral characteristics of MS signals at different energy levels. High-level energy seismic signals are characterized by large amplitudes, low frequencies, relatively concentrated distribution, long vibration duration, and slow attenuation. In addition, the relationship between mining activities and MS events is also statistically analyzed based on the spatial and temporal distribution of MS events with the advancement of working face, and the results show that the increase of vibration frequency and energy can be precursor information for roof pressure. With the advance of the working face, the MS energy has the characteristic of periodic distribution, which is consistent with the periodic weighting revealed by the working resistance of the support. This study provides a reference for further revealing the energy release mechanism of rock burst.
\end{abstract}

\section{Introduction}

With the increase of mining depth, the occurrence conditions of coal seams are more and more complex. The frequency and damage degree of dynamic disasters such as rock burst and coal and gas outburst are increasing day by day [1-3]. Thus, there is an urgent need to develop new technologies and equipment to monitor coal and rock stability in real time. Under the action of ground stress, the formation and expansion of cracks in rock or coal body are accompanied by a large number of MS events. During crack initiation, propagation, and coalescence, the energy accumulated in the rock is dissipated in the elastic waveform, of which the signals can be captured by the MS monitoring system [4]. To reveal the evolution law of MS activity in the process of rock fracture, the frequency spectrum of MS waveform was used to evaluate the danger intensity of rock fracture $[5,6]$. Based on the analysis of field data, Zhang et al. [7] found that the minimum and maximum values of main frequency of MS events in heading face are $14 \mathrm{~Hz}$ and $515 \mathrm{~Hz}$, and the maximum event duration is $1.78 \mathrm{~s}$. Experimental results regarding the microseism signal time-frequency characteristics in the process of fault stick-slip instability indicate that the frequency band of the MS signal before the fault stick-slip is $0 \sim 100 \mathrm{~Hz}$, and the main frequency is within $10 \mathrm{~Hz}$ [8]. The study on the typical intensive rock burst cases under different excavation methods, tunnel boring machine (TBM), and drilling and blasting method 
(D\&B) in deep marble tunnels of Jinping II hydropower station demonstrates that the single day lowest MS main frequency of both TBM and D\&B is less than $200 \mathrm{~Hz}$ during the intensive rock burst development [9]. Wang and Zong [10] applied HHT method to analyze the vibration signals of deep-hole large-charge blasting. The results indicated that the vibration duration of blasting is about $150 \mathrm{~ms}$, and the vibration energy is mainly concentrated in the frequency of 17.75 Hz. Li et al. [11] pointed out that the coal mining MS signals have lower dominant frequency (below $80 \mathrm{~Hz}$ ) and longer vibration duration (more than $2 \mathrm{~s}$ ) than the blasting signals (dominant frequency above $80 \mathrm{~Hz}$ and duration less than $2 \mathrm{~s}$ ). And the following peak envelope curves of the two types of signals fit a power function. The VMD decomposition method is utilized by Zhang et al. [12] to analyze coalrock fracturing and blasting vibration signals. The results show that the energy of the rock fracturing signals is mainly concentrated in the low-frequency modes, whereas the energy of the blasting vibration signals is mainly concentrated in the three high-frequency modes. The main frequency of microseismic signals during coal outflow, blasting, and coal wall collapse is $0.80,0.50$, and $1.00 \mathrm{kHz}$, respectively. The lower frequency part of microseismic signals is mainly contributed by the impact failure, and the higher frequency part is mainly contributed by the coal body caving; additionally, the greater the impact failure, the lower the low-frequency bound of its signal [13]. Scholars have analyzed the frequency spectrum characteristics of a large number of MS events caused by different mining activities and taken their variation laws as the precursor information to predict the occurrence of rock burst [14-16]. Field test results from 8935 working face in Xinzhouyao Coal Mine show that the main frequency spectrum of MS signals before the rock burst is mainly concentrated in 5-60 Hz, and the sharp decrease of the main frequency and the obvious increase of the amplitude of MS signals can be considered as one of the precursors characteristics of rock burst [17]. The S transform (ST) time-frequency analysis technique is introduced to MS signal analysis field by Jiang et al. [18], and the rock failure scale can be investigated based on the frequency characteristic of MS signal. The MS signal transforms from high frequency to low frequency before the obvious rock deformation. Thus, the frequency decrease of MS signal can be regarded as the precursory information of macroscopic deformation of rock mass.

Most of previous research mainly focuses on the distribution of main frequencies of MS signals induced by rock deformation. However, there has been a relative lack of research on the characteristics of MS signals generated by different disturbances with different energy levels. The relationship between energy levels and spectral characteristics of MS signals caused by different mining activities is also fuzzy. Taking the island working face of Liyazhuang Coal Mine (Shanxi Province, China) as the research object, a SOS MS monitoring system was established. Based on the realtime monitoring data of MS activities in the deep rock masses during the mining, this study explored the waveform and spectrum characteristics of MS signal generated by different disturbances with different energy levels. And the MS response characteristics during different mining activities were also studied. And the flowchart of this study is shown in Figure 1.

\section{Engineering Background}

Liyazhuang Coal Mine is the second large-scale mine with design production capacity of $1.5 \mathrm{Mt}$./a coconstructed by China and Romania in Huozhou mining area (north area). The mine is located in Shizhuang District, Huozhou City, Shanxi province, $10 \mathrm{~km}$ away from southwest of Huozhou City (see Figure 2). It has mining area of $30.415 \mathrm{~km}^{2}$, geological reserves of 2.4114 billion tons, and recoverable reserves of 2.1064 billion tons. There are 5 layers of mineable coal seam, and among them $2 \#$ coal seam is the current mining coal seam with average thickness of $3.16 \mathrm{~m}$. Because the average dip angle of coal seam is $6^{\circ}$, the inclined-vertical shaft development is used.

The II228 working face being prepared is the isolated island working face with two completely mined out sections at the upper and lower sides, located in panel 2 of $2 \#$ coal seam with elevation of $+355 \mathrm{~m}$. The advance length and width of II228 working face are $630 \mathrm{~m}$ and $130 \mathrm{~m}$, respectively. The dip angle of coal seam is 4 to $10^{\circ}$, average $6^{\circ}$. The thickness of coal seam is $2.82 \mathrm{~m}$ to $3.45 \mathrm{~m}$, average $2.67 \mathrm{~m}$. Meanwhile, as a complex structural coal seam, it generally contains 2 layers of gangue, mainly mudstone and carbonaceous mudstone.

After entering the deep part of the panel II, influenced by the hilly terrain, the mining depth reaches more than $600 \mathrm{~m}$, leading to the large deformation of the roadway, serious floor heave, and frequent coal burst. The II228 working face currently being prepared is the isolated island working face, where the adjacent two sections have been mined out in the upper and lower sides (see Figure 3 ). It is noted that Figure 3 is a simplified excavation engineering plan of Liyazhuang coal mine, in which some roadways are not drawn, aiming to illustrate the current state and layout of the II228 working face. Affected by factors such as plateau rock stress, mining stress, and gas accumulation, etc., during the driving period, the coal burst occurred frequently, and the drills were frequently ejected or grabbed when drilling, as well as the phenomenon of borehole spraying, which poses serious threat to the underground safety production. According to the analysis of current mining technical conditions, there are multiple factors that may cause the aforementioned dynamic danger phenomena, including the energy accumulated in the coal seam due to high in situ stress, the large elastic energy accumulated in the hard roof of multiple layers, and the accumulated gas internal energy, etc. Therefore, the real-time Polish SOS MS monitoring system is introduced to determine and identify the energy source (hazard source) of the dynamic phenomenon based on the acquired MS signals and further formulate corresponding prediction and prevention methods to guarantee the safe production, meanwhile, providing useful guidance for other panels or mining areas with similar mining conditions. 


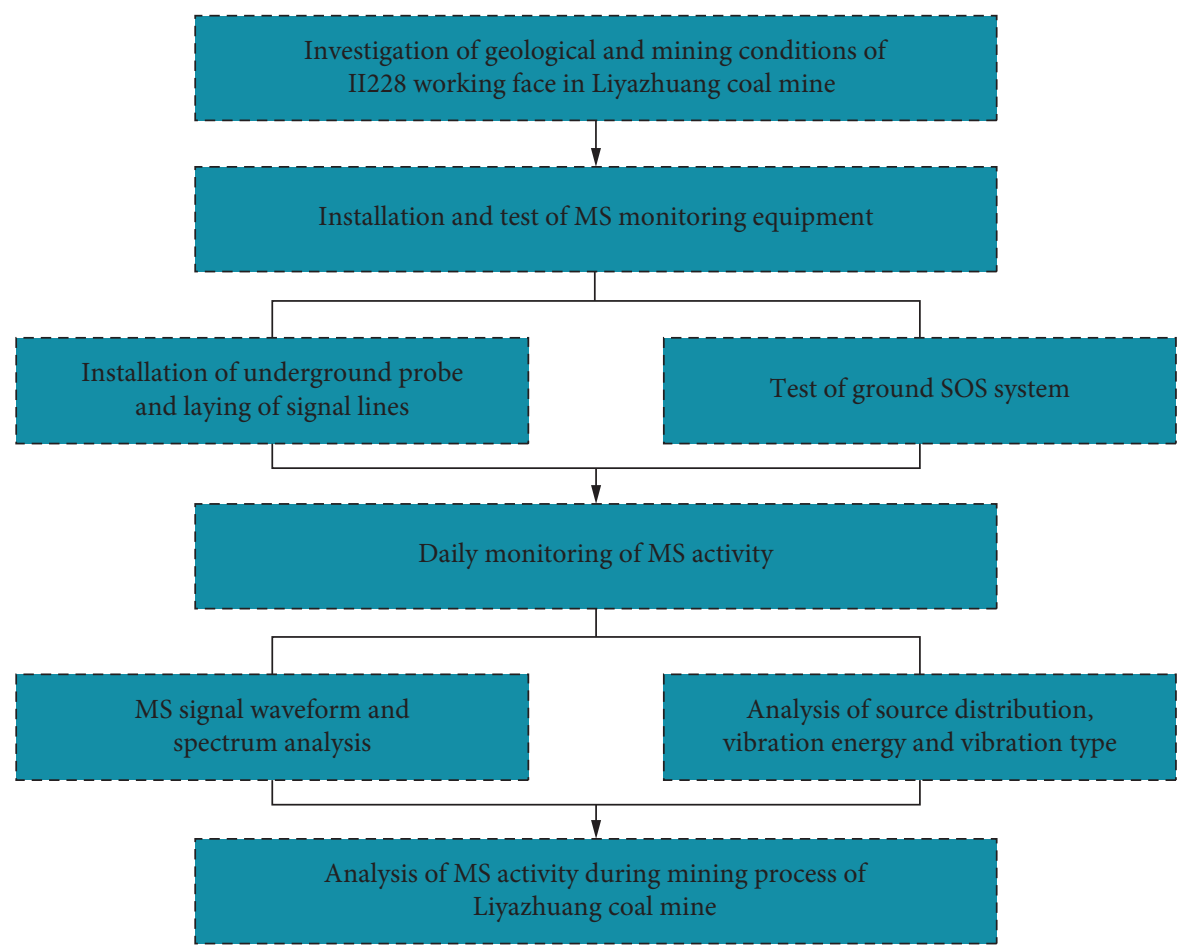

FIgURE 1: The flowchart of this study.

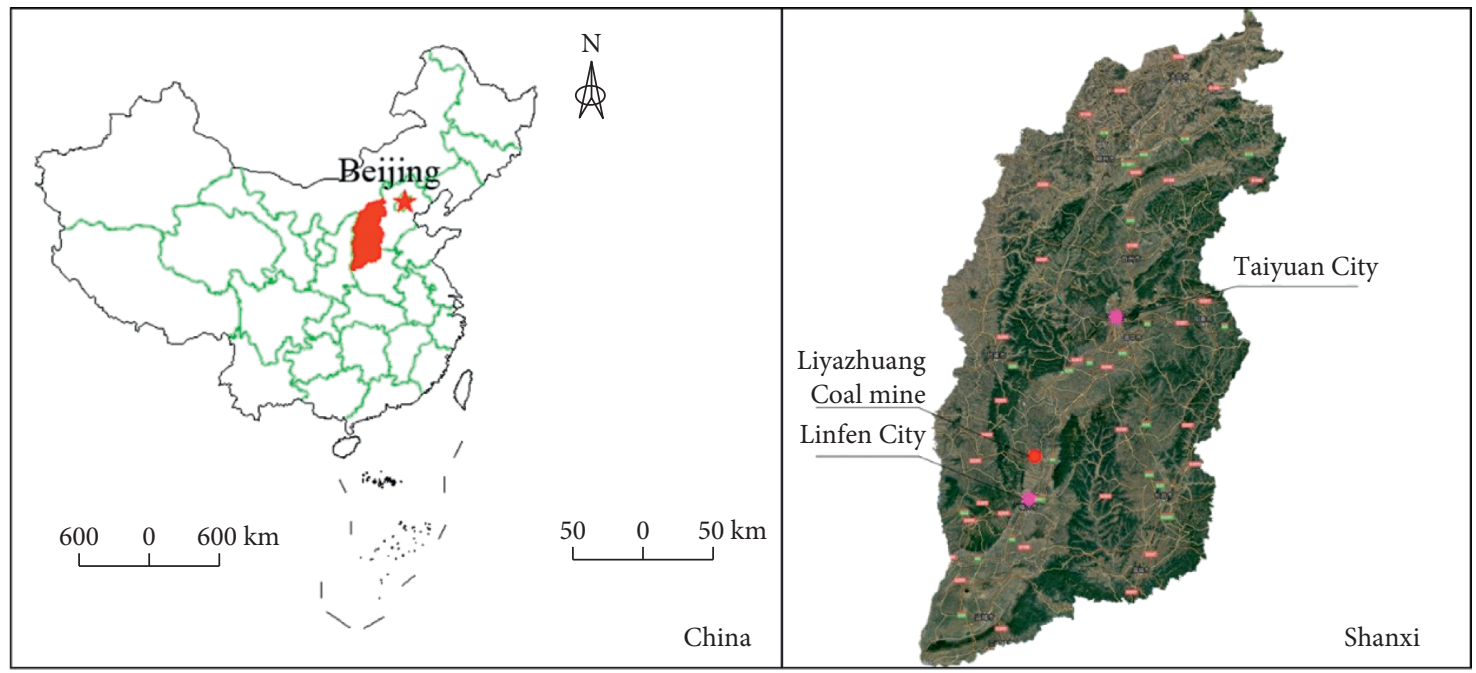

Figure 2: Geographical location of the Liyazhuang Coal Mine.

\section{Establishment of the Polish SOS MS Monitoring System at Liyazhuang Coal Mine}

3.1. Introduction to SOS MS Monitoring System. The SOS MS monitoring system is a new generation product developed and manufactured by the Polish Mining Research Institute. The hardware of this system is composed of three parts, namely, geophone (DLM-2001) with 20 sensors, signals acquisition station (DLM-SO) with 20 channels, and signals recorder (AS-1). DLM-2001 geophone has the function of MS pickup, magnetic transformer signals conversion, signal amplification, etc., of which the sensor is installed vertically on the anchor bolt with a length of $1 \mathrm{~m}$ or more on the bottom floor to facilitate construction, maintenance, and movement. Through the underground cables, the underground acquired signals will be transmitted to the DLM-SO signals acquisition station, of which the function is to rectify and filter the signals; besides, the DLM-SO acquisition station also powers to the geophone. Generally, a set of DLM-SO acquisition station works in conjunction with 16 DLM-2001 geophone sensors that isolate intrinsically safe signals from nonintrinsically safe signals. The current modulated signals in the measuring probe are transmitted through the underground cables into the acquisition station. 


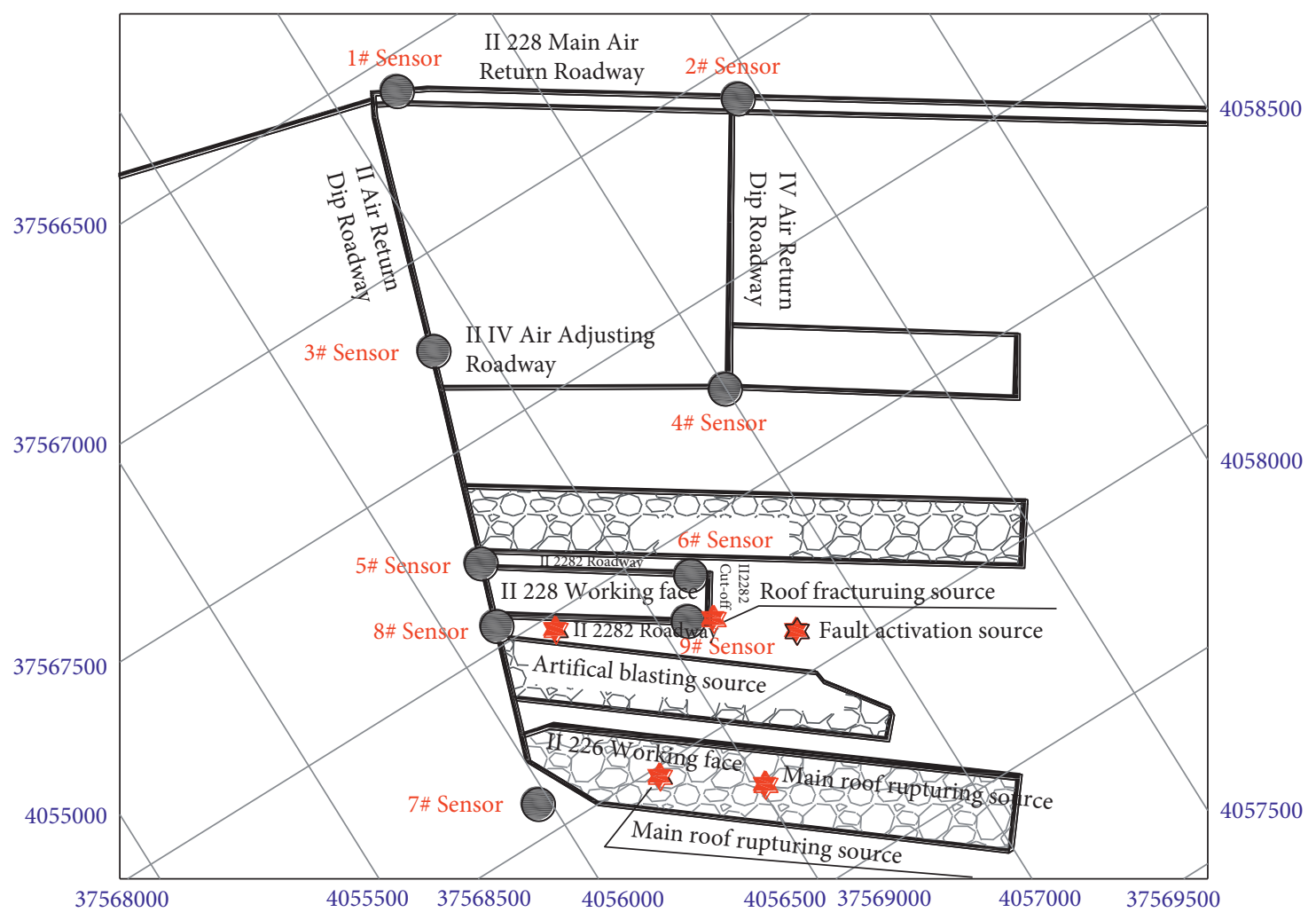

Figure 3: Arrangements of MS stations and partial typical MS events in the Liyazhuang Coal Mine.

In the acquisition station, the signals are accurately reproduced and converted into corresponding voltage signals. The distance between each acquisition station and geophone probe would not exceed $10 \mathrm{~km}$. The AS-1 Seismogram signals recorder is designed based on the IBM PC computer embedded A/D conversion card with 32 channels. Its main function is to convert seismic signals into digital signals.

The software of this system is mainly divided into two parts, namely, Multilok and Seismogram. Multilok is mainly used to complete the three-dimensional position and relevant parameters calculation of the rock vibration source. And Seismogram is used to extract, visualize, and analyze useful MS signals and isolate and screen the wave groups, etc.

SOS MS system can continuously and automatically collect and filter shock signal and accurately calculate the occurrence time, energy, and space three-dimensional coordinates of shock event $(>100 \mathrm{~J})$. Its maximum sampling rate is $2500 \mathrm{~Hz}$. The frequency bandwidth of MS signals that can be monitored by this system is $1-600 \mathrm{~Hz}$.

\subsection{Planning the MS Monitoring System}

3.2.1. Basic Theory of MS Location. Effectively and accurately detecting and locating the MS events, which contain a large amount of information about rock and coal fracture, is of important significance to detect potential dangers and further mitigate hazards [19]. In terms of the range and scale of coal mine field, the $P$-wave is often chosen for locating the MS events because of its advantages of high accuracy. The positioning principle of the MS monitoring system is to use the time difference of the $P$-wave under a specific wave velocity field to determine the rock failure point and further perform two-dimensional or three-dimensional MS source location. Besides, the energy released in the duration of the MS can be also calculated. In practical application, it is often assumed that the coal body is homogeneous and isotropic. That is, the velocity of $P$-wave in each direction is a constant. Thus, for homogeneous and isotropic velocity models, the time from the MS source $H=\left(X_{0}, Y_{0}, Z_{0}\right)^{T}$ to the sensor $i$ can be calculated:

$$
T_{i}\left(H, V, X_{i}\right)=\frac{\sqrt{\left(x_{0}-x_{i}\right)^{2}+\left(y_{0}-y_{i}\right)^{2}+\left(z_{0}-z_{i}\right)^{2}}}{V_{P}},
$$

where $X=\left(x_{i}, y_{i}, z_{i}\right)$ is the coordinate of the sensor $i$; $t_{0}$ is the time when the MS occurs; $t_{i}$ is the time when the $P$-wave reaches the sensor $i$; $V_{P}$ is the velocity of $P$-wave; $i=1,2, \ldots$, $n, n$ is the number of sensors installed. From the above formula, it can be seen that at least four sensors are needed providing enough data to solve the equation.

3.2.2. Sensors Layout and Installation. The II 228 working face in panel 2 is the key area for rock burst prevention and control, and it is also the important area for MS monitoring, which can provide useful information for rock burst prediction. Besides, the panel 2 in coal seam $2 \#$ has the risk of rock burst, so the monitoring stations should be arranged as close as possible to this area, and sufficient distribution density should be satisfied. Thus, based on the MS location 
theory and MS monitoring principle [20, 21], 11 sensors were designed to install around the II228 working face, and the detailed coordinates for the 11 MS sensors are listed in Table 1. The map of the network topology of the MS monitoring system is shown in Figure 3. And the system diagram is shown in Figure 4.

Depending on the MS sensor used, the detector probe can be installed vertically on the drilling bolt with a depth of more than $1 \mathrm{~m}$ and an error of 10 degrees (the probe is fixed to the M2O-bolt thread). To ensure the good operation of MS sensors, the transmission lines of MS network should be well and tightly connected. Therefore, under the condition that the positive and negative electrodes are correct, the probe output cable should be connected through the specially made explosion-proof sleeve or junction box. The schematic of MS sensors installation can be seen in Figure 5.

\subsubsection{The Verification of Location Accuracy of Monitoring} System. The location accuracy of MS monitoring system is the foundation of the prevention and early warning of rock burst. Thus, the precision of source positioning must be validated after installation of the MS monitoring system. A common approach is to compare positioning results with actual locations of blasting activities, which provide a useful assessment on the validity of sensor's spatial distribution and performance of the entire system. To ensure the calculation accuracy of the position and source parameters of MS events, we also performed a location accuracy test of the MS events. Their places in panel 2 were chosen as the blasting positions. The coordinates of the blasting points determined through three artificial explosions at 3 positions showed a maximum error of $5.93 \mathrm{~m}$ and a minimum error of $1.85 \mathrm{~m}$ against the actual points, which meets the requirement for studying MS activities in the field monitoring. The reliability of the equipment is verified through this test. On the other hand, the rationality of sensors layout is also validated. The detailed data of blasting location and estimated locations are listed in Table 2.

\section{Results and Analysis}

4.1. The Spectrum Characteristics of MS Signals of Mining Tremor with Different Energy Levels in Liyazhuang Coal Mine. Under the effect of external disturbances, dynamic failures would occur in the rock mass. In the process of rock failure, detectable acoustic and seismic signals would be produced, accompanied by the release of energy which can be monitored by the MS monitoring system. Due to the different failure mechanism of rock and coal, the monitored energy is in different magnitudes $[22,23]$. According to the focal mechanisms of mine tremors, the characteristics of MS signals produced by various types of seismic sources are different, including energy, frequency spectrum, etc. $[24,25]$. Previous studies have shown that there may be a relation between the MS energy and spectrum [26]. Thus, it is necessary to analyze the waveform and spectrum characteristics of MS signals with different energy levels and further provide the theoretical basis for identifying the types of mining-induced disturbances. It is also of important significance to take corresponding preventive measures for the occurrence of the rock burst or other dynamic disasters induced by different mining disturbances. This section mainly aims at analyzing the spectrum characteristics of MS signals with different energy levels monitored and recorded in Liyazhuang Coal Mine.

The energy of MS events recorded by the MS monitoring system in Liyazhuang Coal Mine was mainly concentrated between $10^{2}$ and $10^{5} \mathrm{~J}$. Figure 6 shows the waveform and spectrum variation characteristics of MS events with energy greater than $10^{4} \mathrm{~J}$. From Figures 6(a) and 6(c), it can be seen that the amplitudes (vibration velocity) of MS signals mainly concentrate in $(0.6-6.5) \times 10^{-4} \mathrm{~m} / \mathrm{s}$. The signal attenuation is fast, lasting from $800 \mathrm{~ms}$ to $1000 \mathrm{~ms}$. Meanwhile, it also can be known that the MS signals monitored by sensors with different distances from the same vibration source have similar amplitudes. However, the closer the vibration source is, the longer the MS signals received by the sensor will last. From Figure 6(b), it can be seen that the main frequency is about $50 \mathrm{~Hz}$ and most of the amplitude is concentrated in the frequency bands between $25 \mathrm{~Hz}$ and $100 \mathrm{~Hz}$, while from Figure 6(b), it can be known that the main frequency is about $60 \mathrm{~Hz}$ and most of the amplitude is concentrated in the frequency bands between $36 \mathrm{~Hz}$ and $90 \mathrm{~Hz}$. They have similar characteristics of main frequency distributions. However, the closer the vibration source, the larger the amplitude spectrum of the signals. Generally, the seismic wave continuously attenuates along the rock medium, so that the MS signals monitored by the station closer to the vibration source may have more useful information.

Figure 7 shows the waveform and spectrum variation characteristics of MS events with energy of $1050.7183 \mathrm{~J}$. It can be seen that the amplitudes (vibration velocity) of MS signals mainly concentrate in $(0.2-5) \times 10^{-4} \mathrm{~m} / \mathrm{s}$, and the MS signals last about $600 \mathrm{~ms}$. In terms of the spectrum, the frequency band of the signal is $0-160 \mathrm{~Hz}$. Besides, the main frequency bands range is about $10-75 \mathrm{~Hz}$ and most amplitude concentrates on the frequency bands of $10-50 \mathrm{~Hz}$. Generally, the MS signals with such waveform characteristics and vibration energy of about $10^{3} \mathrm{~J}$ are generated by the underground artificial blasting.

Figure 8 shows the waveform and spectrum variation characteristics of MS events with energy of $871.7724 \mathrm{~J}$. Obviously, the amplitudes (vibration velocity) of MS signals mainly concentrate in $(0.2-0.6) \times 10^{-4} \mathrm{~m} / \mathrm{s}$, and the MS signals last about $550-750 \mathrm{~ms}$. And the frequency band of the signal is $0-120 \mathrm{~Hz}$, while the main frequency bands range is about $15-80 \mathrm{~Hz}$.

As shown in Table 3, it can be concluded that the higher the vibration energy is, the longer the corresponding MS signals would last, and the larger the amplitude (vibration velocity) is. In addition, for the MS signals with high energy levels, the frequency is wide, but the main frequency band is narrow but centralized. Generally, the MS signals generated by strong vibration are characterized by large amplitude and low frequency, while the signals of vibration with low energy level have the characteristic of wide main frequency band. In most practical cases, the magnitude and the energy concentration degree of MS events were identified as the criteria 
TABLE 1: The three-dimensional coordinates of MS sensors.

\begin{tabular}{lccc}
\hline No. & \multicolumn{1}{c}{ Coordinate } & \multicolumn{1}{c}{} \\
& $X$ & 4057296.00 & -321.5 \\
1 & 37566700.00 & 4058164.00 & -363.8 \\
2 & 37567261.00 & 4056877.00 & -275 \\
3 & 37567733.00 & 4057494.00 & -294.5 \\
4 & 37568230.00 & 4056688.00 & -228 \\
5 & 37568281.00 & 4057151.00 & -235 \\
6 & 37568599.00 & 4056468.00 & -202 \\
7 & 37568911.00 & 4057494.00 & -294.5 \\
8 & 37568230.00 & 4056468.00 & -202 \\
9 & 37568911.00 & & \\
\hline
\end{tabular}

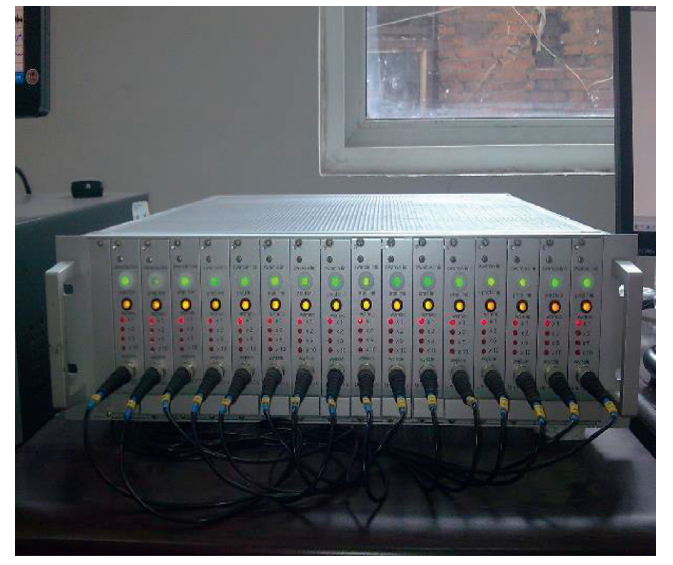

(a)

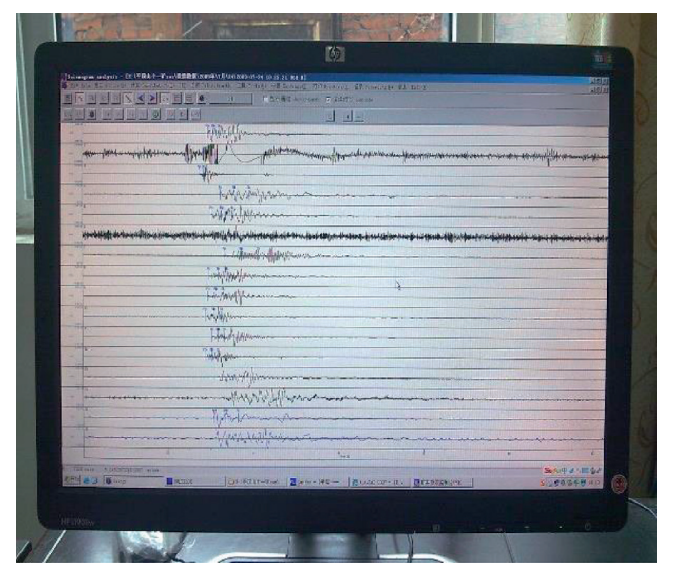

(c)

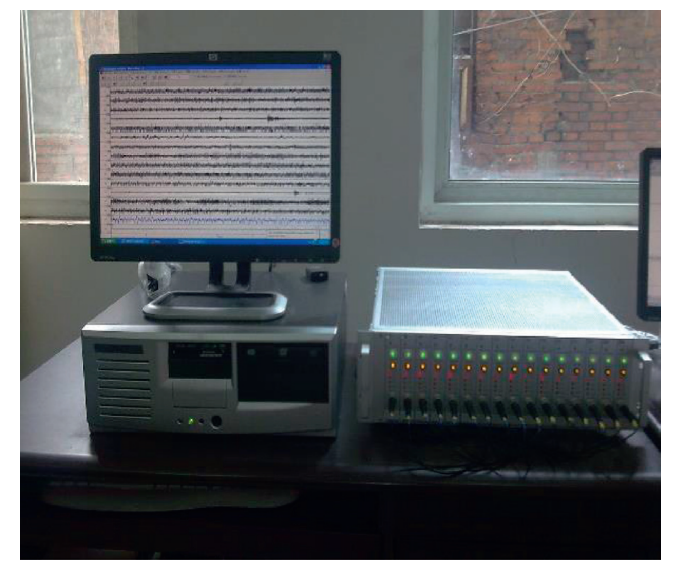

(b)

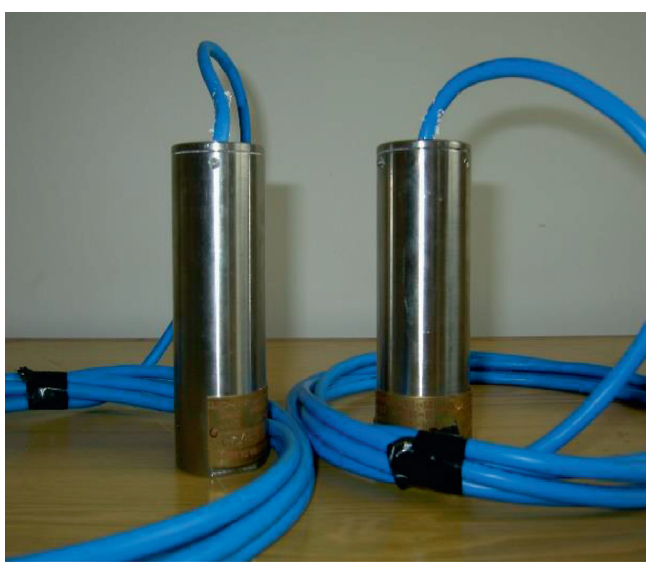

(d)

FIGURE 4: The schematic of MS sensors installation. (a) DLM-SO signal acquisition station (16 channels). (b) Recording instrument. (c) Analysis meter. (d) Detection and measurement probe.

for rock burst hazards [27]. Generally, the minimum energy at which the rock burst occurs is $10^{3} \mathrm{~J}$, and most rock bursts start from $10^{5} \mathrm{~J}$. The area where the MS events with the energy magnitude of $10^{5}$ or above frequently occur can be considered as the high-risk area [28-30].

4.2. The Spectrum Characteristics of MS Signals Induced by Typical Underground Disturbances. Mining activity and tectonic activity are known to pose external disturbances on the rock and coal mass, resulting in the damage of the rock and coal mass. Under different disturbances, the MS signals generated by the rock and coal failure have different characteristics due to the different failure mechanics of rock and coal mass [31-34]. Therefore, it is of practical significance to identify different focal sources and further make corresponding preventive measures by analyzing the waveform and spectrum characteristics of MS signals generated under different disturbance conditions. 


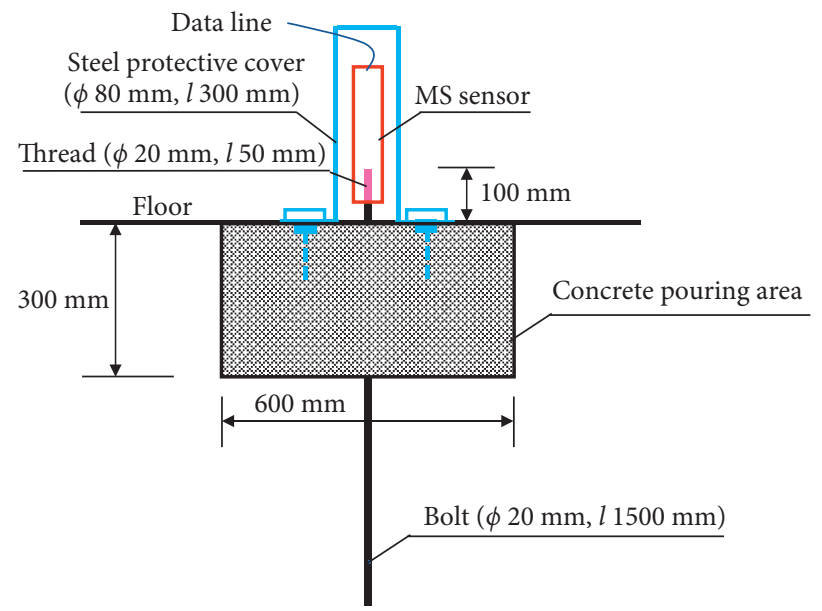

FIgURE 5: The schematic of MS sensors installation.

TABLE 2: The comparison of the three-dimensional coordinates of actual points and estimated location.

\begin{tabular}{|c|c|c|c|c|c|}
\hline No. & & dinate & & rdinate & Error \\
\hline & $X$ & 37568453.68 & $X$ & 37568448.32 & 5.36 \\
\hline 1 & $Y$ & 4056695.32 & $Y$ & 4056701.14 & 5.82 \\
\hline & $Z$ & -224.52 & $Z$ & -227.08 & 2.56 \\
\hline & $X$ & 37568613.02 & $X$ & 37568608.87 & 4.3 \\
\hline 2 & $Y$ & 4056939.97 & $Y$ & 4056845.45 & 5.48 \\
\hline & $Z$ & -231.1 & $Z$ & -233.26 & 1.85 \\
\hline & $X$ & 37568673.14 & $X$ & 37568677.23 & 4.09 \\
\hline 3 & $Y$ & 4057176.65 & $Y$ & 4057182.58 & 5.93 \\
\hline & $Z$ & -233.54 & $Z$ & -236.31 & 2.77 \\
\hline
\end{tabular}

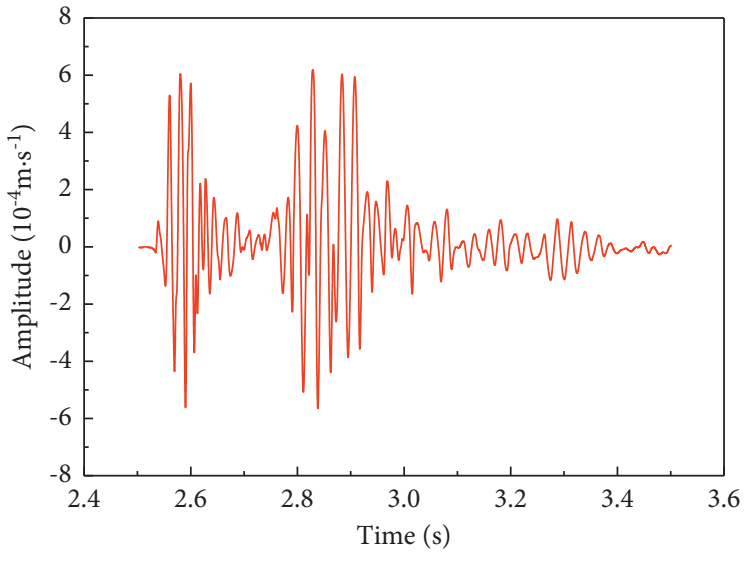

(a)

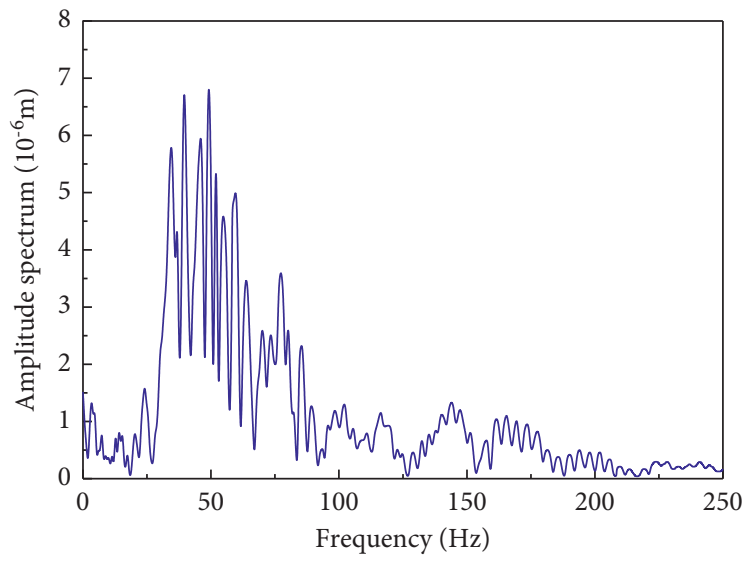

(b)

FIgURE 6: Continued. 


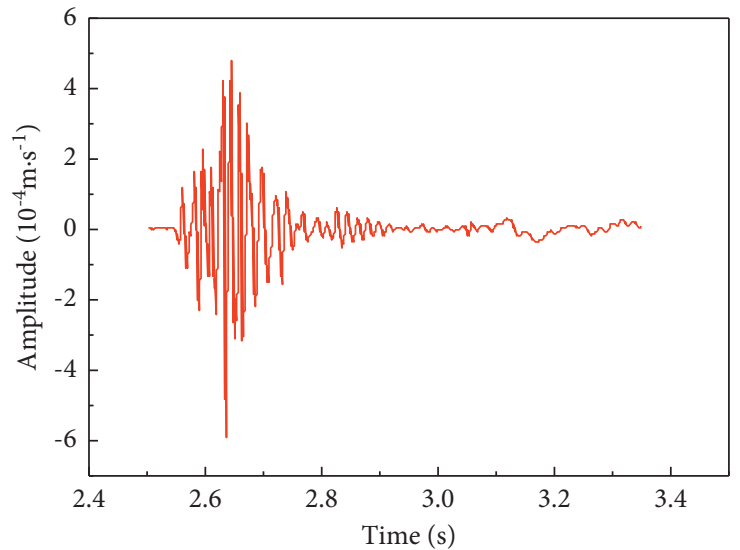

(c)

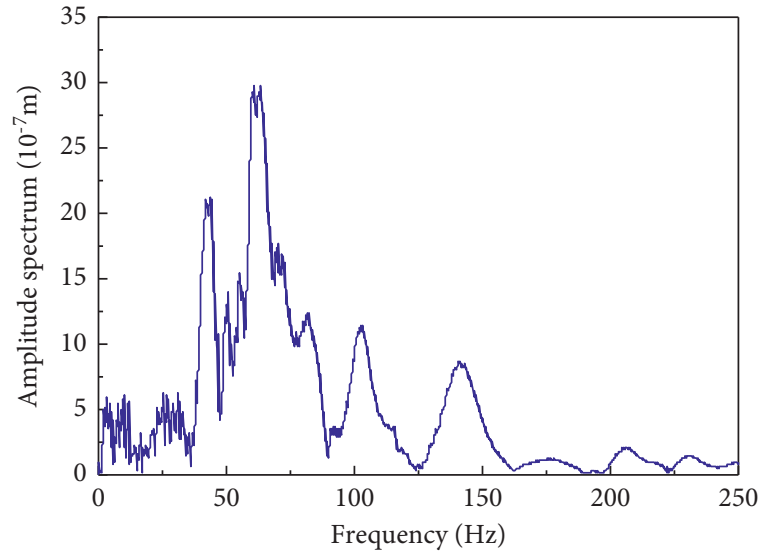

(d)

Figure 6: Curves of vibration velocity-time and amplitude spectrum-frequency with vibration energy $=39932.22 \mathrm{~J}$. (a) Vibration velocitytime (sensor 6\#). (b) Amplitude spectrum-frequency (sensor 6\#). (c) Vibration velocity-time (sensor 9\#). (d) Amplitude spectrum-frequency (sensor 9\#).

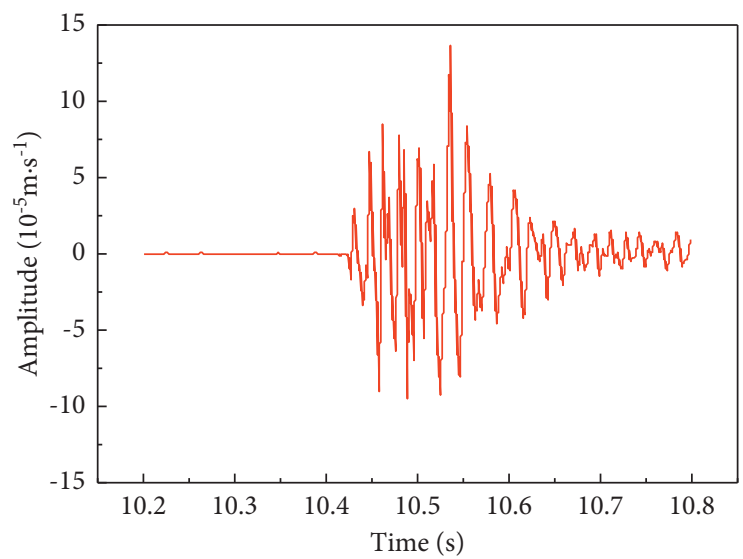

(a)

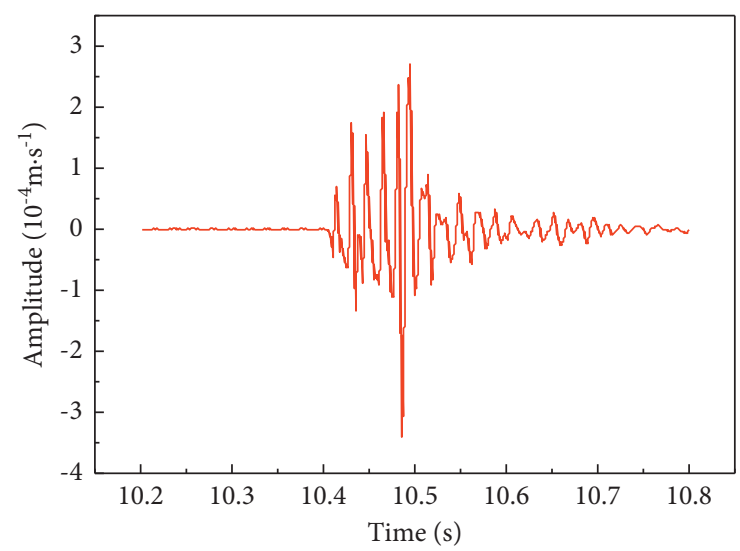

(c)

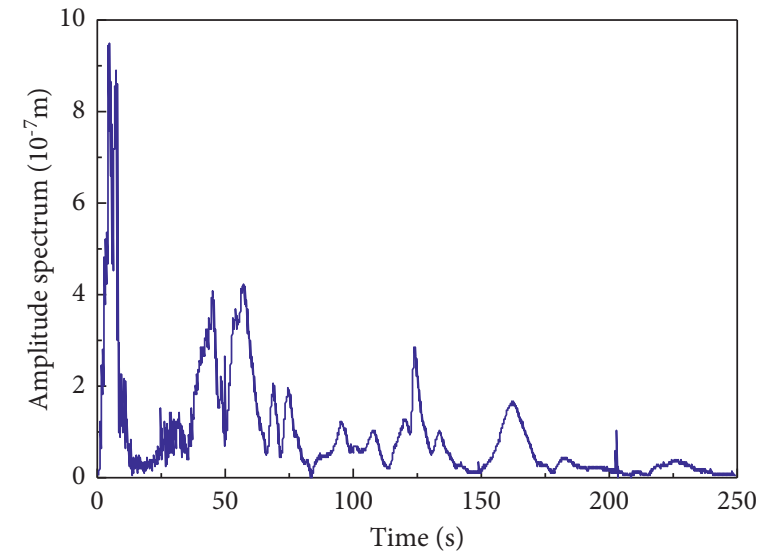

(b)

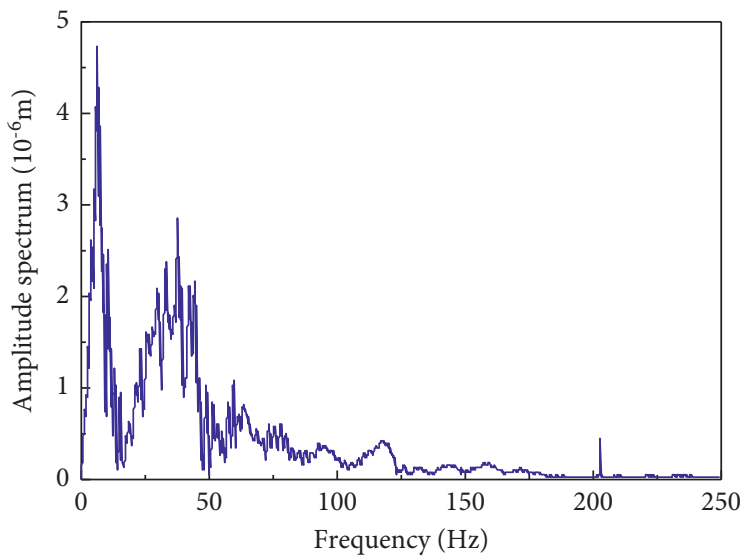

(d)

FIGURE 7: Curves of vibration velocity-time and amplitude spectrum-frequency with vibration energy $=1050.7183 \mathrm{~J}$. (a) Vibration velocitytime (sensor 6\#). (b) Amplitude spectrum-frequency (sensor 6\#). (c) Vibration velocity-time (sensor 9\#). (d) Amplitude spectrum-frequency (sensor 9\#). 


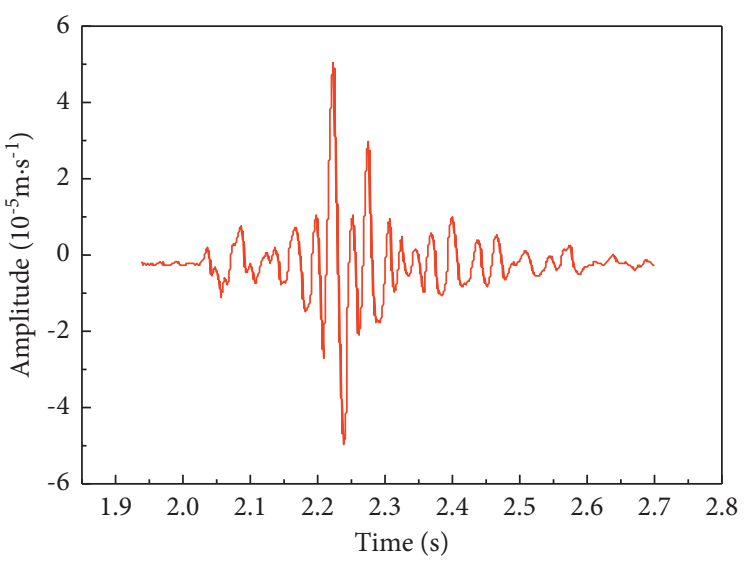

(a)

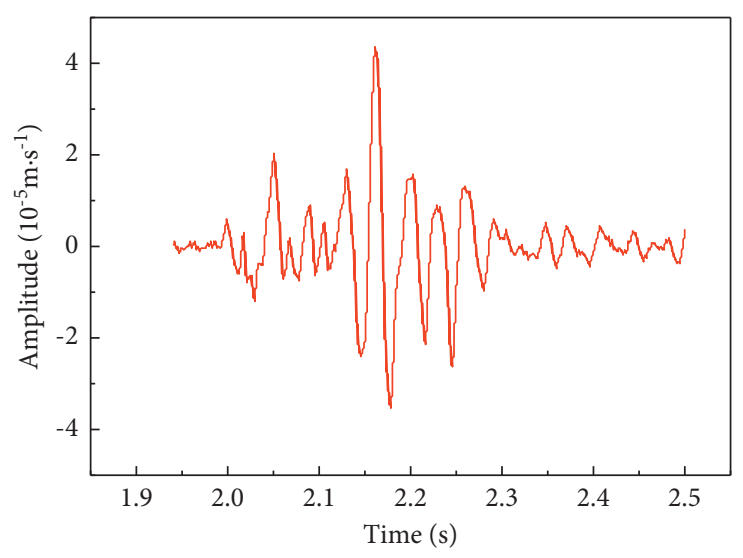

(c)

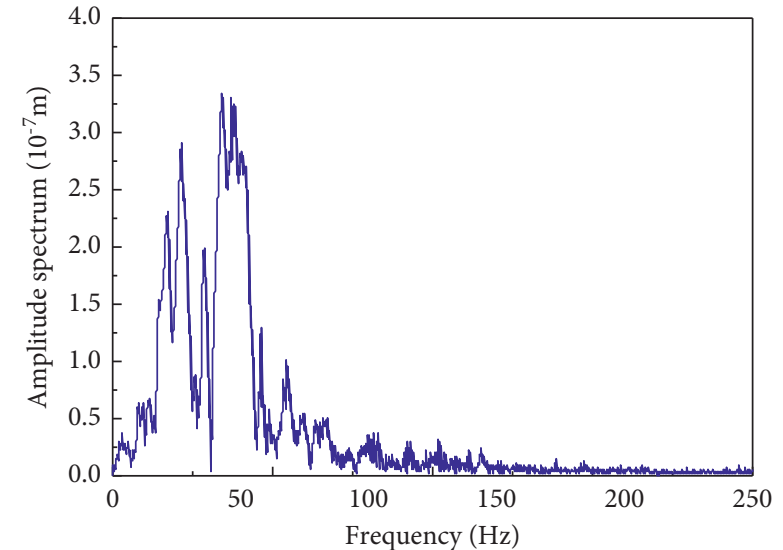

(b)

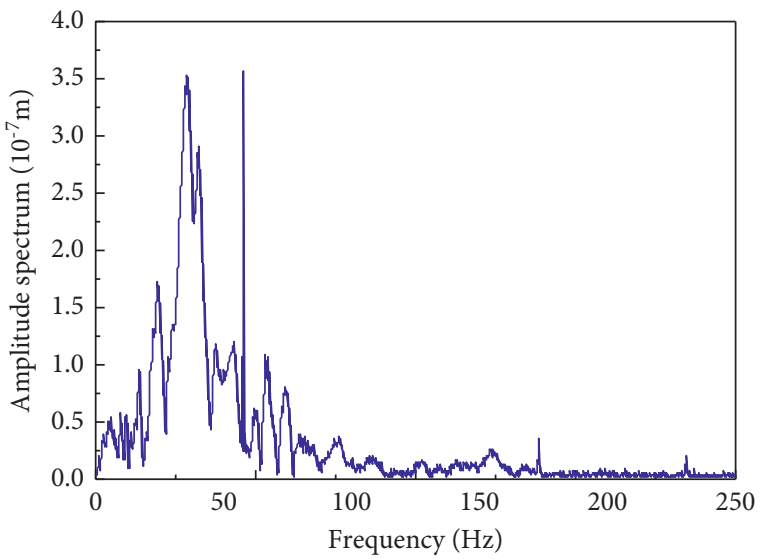

(d)

Figure 8: Curves of vibration velocity-time and amplitude spectrum-frequency with vibration energy $=871.7724 \mathrm{~J}$. (a) Vibration velocitytime (sensor 6\#). (b) Amplitude spectrum-frequency (sensor 6\#). (c) Vibration velocity-time (sensor 9\#). (d) Amplitude spectrum-frequency (sensor 9\#).

TAвLe 3: Comparison of MS signals with different energy levels monitored in Liyazhuang Coal Mine.

\begin{tabular}{lccccc}
\hline Energy levels $(\mathrm{J})$ & Duration $(\mathrm{ms})$ & Amplitude $(\mathrm{m} / \mathrm{s})$ & Attenuation rate & Frequency bands & Main frequency $(\mathrm{Hz})$ \\
\hline $10^{4}$ & $800-1000$ & $(0.6-6.5) \times 10^{-4}$ & Slow & $0-200$ & $40-70$ \\
$10^{3}$ & $600-800$ & $(0.2-0.5) \times 10^{-4}$ & Fast & $0-160$ & $10-75$ \\
$10^{2}$ & $550-750$ & $(0.2-0.6) \times 10^{-4}$ & Faster & $0-120$ & $15-80$ \\
\hline
\end{tabular}

By MS monitoring and analysis, in the advancement of working face, several typical shock events (Figure 3) occurred around the II228 working face. Figure 9 shows the waveforms of typical seismic signals and Figure 10 shows the corresponding curves of amplitude spectrum-frequency.

On May 5, 2011, a vibration was detected at the rear of 226 working face at 6:53:10 (Figure 3). According to the analysis of SEISGR and Multilok software, the geographical coordinates of the shock event were (37569200.00, $4057027.00,-220.14)$, and the vibration energy was $1.78 \times 10^{3} \mathrm{~J}$. And the vibration waveform was generated by the immediate roof falling in the gob (Figure 9(a)). From Figure 10(a), the main frequency bands range is about $0-100 \mathrm{~Hz}$ and the maximum energy concentrates on the frequency bands of $25-35 \mathrm{~Hz}$.
On May 6, 2011, a vibration was detected at the rear of 226 working face at 16:51:36 (Figure 3). According to the analysis of SEISGR and Multilok software, the geographical coordinates of the shock event were (37569035.71, 4056781.66, -232.14), and the vibration energy was $2.72 \times 10^{4} \mathrm{~J}$. And the vibration waveform was a typical waveform of main roof rupturing (Figure 9(b)). From Figure 10(b), the main frequency bands range is about $0-140 \mathrm{~Hz}$ and the maximum energy concentrates on the frequency bands of $20-40 \mathrm{~Hz}$.

On May 10, 2011, a major shock event appeared in a large fault near the cut-off of the II228 working face at 23:05:53 (Figure 3). It can be confirmed this shock event was induced by fault activation by signal waveform analysis and MS locating. And 7 sensors arranged in the II and IV mining 


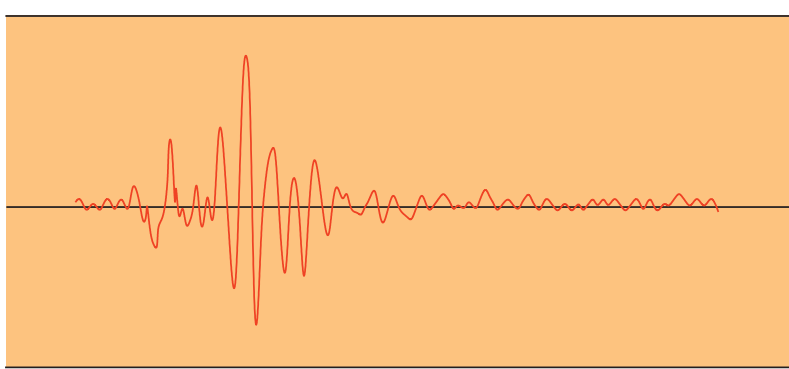

(a)

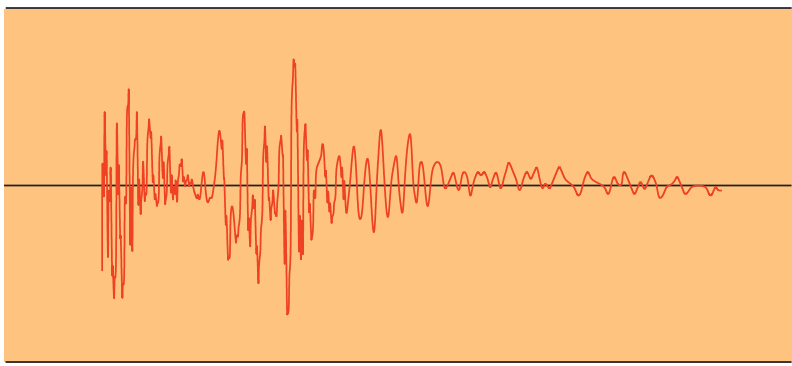

(c)

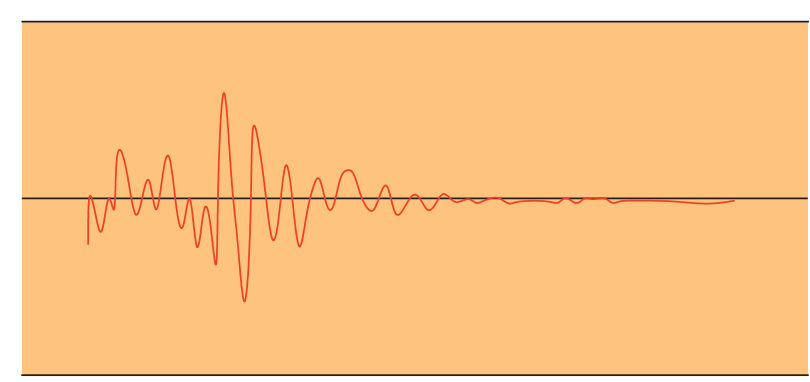

(b)

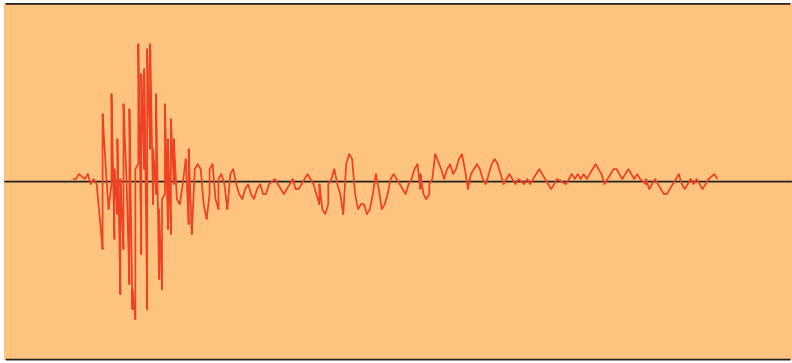

(d)

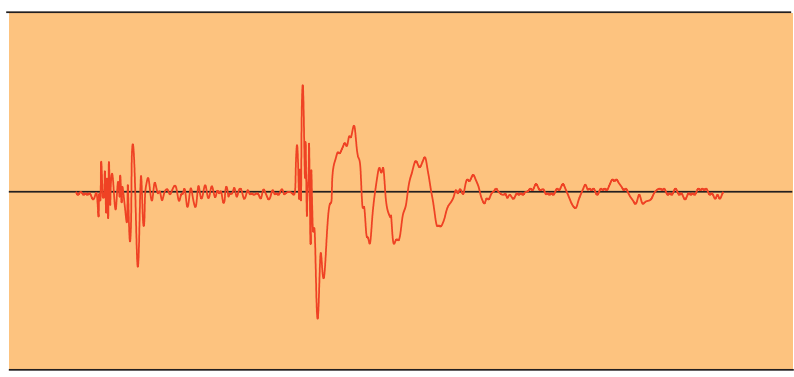

(e)

FiguRE 9: Waveforms of typical seismic signals. (a) Immediate roof rupturing in the gob. (b) Main roof rupturing in the gob. (c) Fault activation. (d) Roof fracturing in the cut-off. (e) Artificial blasting in the drilling site.

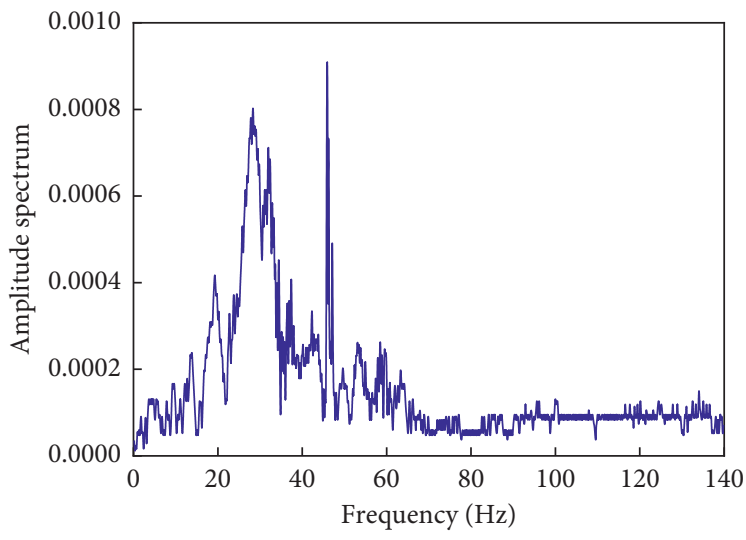

(a)

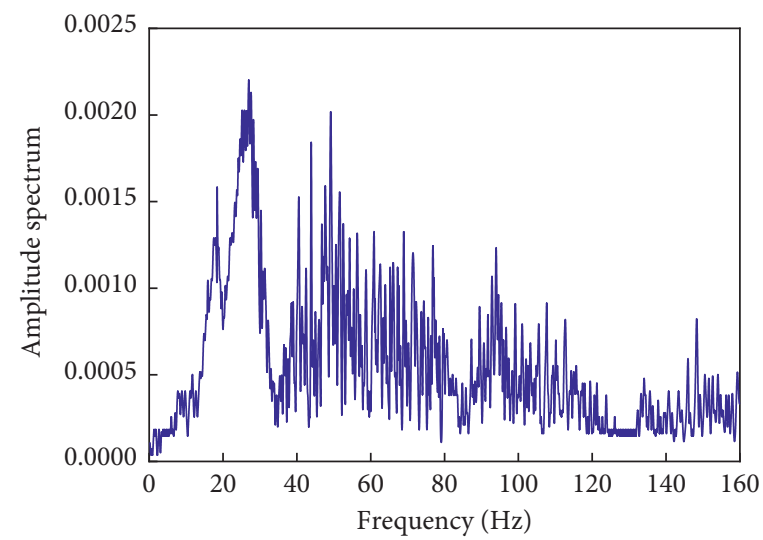

(b)

Figure 10: Continued. 


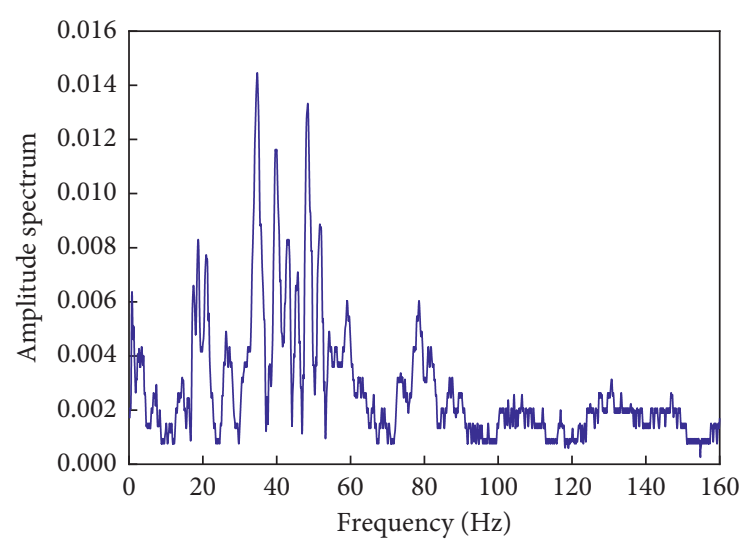

(c)

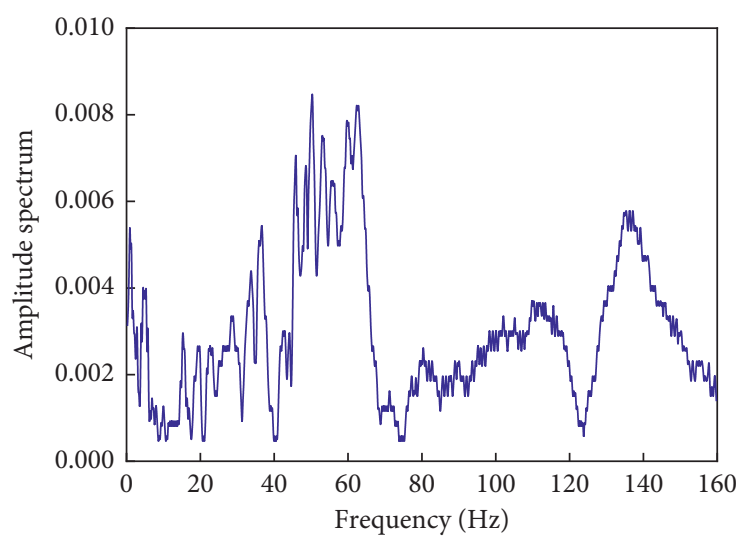

(d)

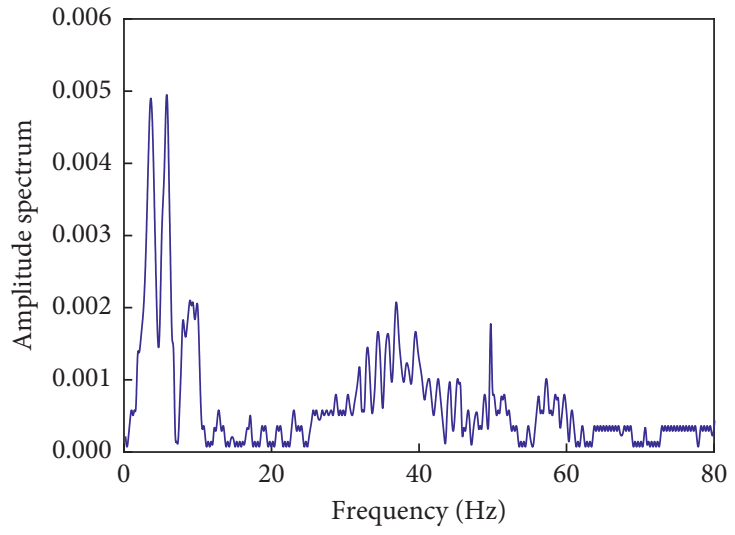

(e)

FIGURE 10: Curves of amplitude spectrum-frequency. (a) Immediate roof rupturing in the gob. (b) Main roof rupturing in the gob. (c) Fault activation. (d) Roof fracturing in the cut-off. (e) Artificial blasting.

areas have recorded the vibration information, indicating that the vibration energy is really large. According to the analysis of SEISGR and Multilok software, the geographical coordinates of the shock event were (37568889.84, $4057308.61,-217.87)$, and the vibration energy was $2.78 \times 10^{5} \mathrm{~J}$. Figure 9 (c) shows the waveform of this vibration. And the corresponding frequency spectrum is obtained by using the fast Fourier transform method, as shown in Figure 10(c). Obviously, the main frequency bands range is about $0-120 \mathrm{~Hz}$ and the maximum energy concentrates on the frequency bands of $35-55 \mathrm{~Hz}$.

On May 15, 2011, a mine seismicity with high energy occurred near the cut-off of the II228 working face at 22: 14:20 (Figure 3). According to the analysis of SEISGR and Multilok software, the geographical coordinates of the shock event were (37568718.80, 4057133.48, -240.56), and the vibration energy was $1.38 \times 10^{4} \mathrm{~J}$. From the location and the vertical elevation of the epicenter source, the vibration was caused by the roof fracturing due to the high stress superimposing at the II228 cut-off. The vibration waveform was shown in Figure 9(d). After waveform attenuation, there are still large fluctuations in the tail, which is obviously different from roof fracturing in the gob and artificial blasting. From Figure 10(d), the main frequency bands range is about $0-160 \mathrm{~Hz}$ and the maximum energy concentrates on the frequency bands of $40-80 \mathrm{~Hz}$. Besides, the spectrum is relatively scattered. Although the amplitude and frequency of the wave caused by the vibration were relatively large, there was no rock burst occurring. This is because the vibration energy did not reach the average energy level required for the occurrence of rock burst under normal conditions; on the other hand, the location of the seismic source was deep, so the energy is attenuated to some extent during the propagation process.

On June 10, 2011, a vibration was detected at the NO.3 high-level drilling site near the II228 working face at 00:26: 52 (Figure 3). According to the analysis of SEISGR and Multilok software, the geographical coordinates of the shock event were (37568545.00, 4056767.00, -224.06), and the vibration energy was $1.2 \times 10^{3} \mathrm{~J}$. The vibration waveform was typical artificial blasting (Figure $9(\mathrm{e})$ ), and the vibration information was recorded by 4 sensors arranged at II228 working face. Figure 10(e) shows the variation characteristics of corresponding frequency spectrum. It was found that the main frequency bands range is about $0-60 \mathrm{~Hz}$ and the maximum energy concentrates on the frequency bands of $0-10 \mathrm{~Hz}$. 
From above analysis, it also can be found that the vibration waveform caused by main roof fracturing is similar to that of the immediate roof fracturing, but their spectrum is different. The main frequency of the waveform generated by the main roof fracturing is lower than that of the immediate roof fracturing, and the energy generated by the former is generally much higher than that of the latter. The energy released by roof fracturing is basically the same as that of artificial blasting, but the waveform is obviously different. Besides, the frequency bands which the maximum energy concentrate on are also different.

\subsection{MS Response Characteristics during Mining Activities and Roof Weighting}

4.3.1. Variation of MS Events in the Normal Production Process. Generally, underground vibration caused by mining activities can be roughly divided into two categories. One type is directly caused by mining activities, including locomotive operation, loading loaders operation, artificial blasting, etc. The other is caused by the instability failure of surrounding rock due to mining activities. The SOS MS monitoring system can monitor, record, and preserve various vibration signals in real time, so as to locate the vibration source and calculate the magnitude of vibration energy.

(1) Temporal Distribution of MS Events. Figure 11 shows the variation of MS events near II226 working face in different periods of a day. More MS events occur in the period of normal production, while relatively less MS events occur in the period of handover and overhaul. Although the production time of Liyazhuang Coal Mine is not the same every day, in statistics, the frequency of MS events occurring near the working face in the period of normal production is twice that of the inspection time. For instance, during the shift period (14:00-16:00), as the mining activities reduce, the frequency of MS events is correspondingly reduced to a minimum. And after shift period (16:00-18:00), as mining activity increases, the frequency of MS events is also increased. Thus, it can be concluded that there exists a good correspondence between the frequency variation of MS events and mining activities, which validates the reliability of the SOS MS monitoring system from another prospective. Meanwhile, it also can be found that the MS events will not disappear immediately after stopping mining activities at working face, indicating that it would take some time for the surrounding rock to return to stability after the stopping of mining disturbance.

(2) Spatial Distribution of MS Events. Figure 12 shows the distribution of the MS events in daily production. The MS events are mainly concentrated in two zones: the first MS events concentration zone lies close to the II228 working face. In this zone, most MS events with high energy were mainly caused by the roof separation in front of the working face and roof fracturing and caving behind the working face. The second MS events concentration zone is the high-level drilling site, where most MS events were mainly generated by the artificial blasting. In this zone, a high-level drainage roadway was being excavated. Thus, artificial blasting was carried out every day. On the other hand, the release of internal elasticity of rock strata due to the change of in situ stress caused by excavation may produce more MS events. In addition, it can be easily found that, with the advancement of II228 working face, the location of MS events also changed. Generally, the distribution of MS events is affected by mining activities, both spatially and temporally. The energy of these vibrations is generally below $10^{3} \mathrm{~J}$, which has no great influence on the occurrence of dynamic disasters.

\subsubsection{Relationship between MS Events and Periodic} Weighting of Working Face. To study the periodic weighting in the II226 working face, the real-time monitoring of hydraulic support working resistance was applied in the field. The measurement stations were arranged along the direction of working face. In the process of periodic pressure analysis, the sum of the average end-cycle resistance of the hydraulic support and its mean variance is taken as the main index to judge the periodic pressure. It can be calculated as

$$
\begin{aligned}
& \sigma_{P}=\sqrt{\frac{1}{n} \sum_{i=1}^{n}\left(P_{t i}-\overline{P_{t}}\right)^{2},} \\
& \overline{P_{t}}=\frac{1}{n} \sum_{i=1}^{n} P_{t i},
\end{aligned}
$$

where $\sigma_{P}$ is the mean variance of the average end-cycle support resistance; $n$ is the number of cycles; $P_{t i}$ is the endcycle support resistance in the $i$ th cycle; $\overline{P_{t}}$ is the average value of the end-cycle support resistance.

The criterion for the roof weighting can be expressed as

$$
P_{t}^{\prime}=\overline{P_{t}}+\sigma_{P}
$$

After calculation, the weighting criterion of each support is shown in Table 4.

Figure 13 shows the variation characteristics of periodic end-cycle support resistance of each support. The red lines indicate the weighting criterion, and the green lines indicate the weighting position.

Table 5 shows the statistics of periodic weighting time of each support in June, and Figure 14 shows the daily number and energy of MS events before and after three periodic weighting times in June. The column represents the daily total energy and the red line represents the daily numbers of MS events. The three times of periodic weighting of II226 working face were on June 5, 13, and 23, respectively. From Figures 13 and 14, with the breakage occurring in the main roof, the hydraulic support pressure increases periodically in the time of roof weighting. Two days before the period weighting, the daily average number of monitored vibrations was about 11 times, and the number of vibrations showed an increasing trend; the total energy of daily monitored vibrations was about $4500 \mathrm{~J}$, of which the daily maximum vibration energy was $1800 \mathrm{~J}$, and the overall vibration energy also showed an increasing trend. This increase of vibration 


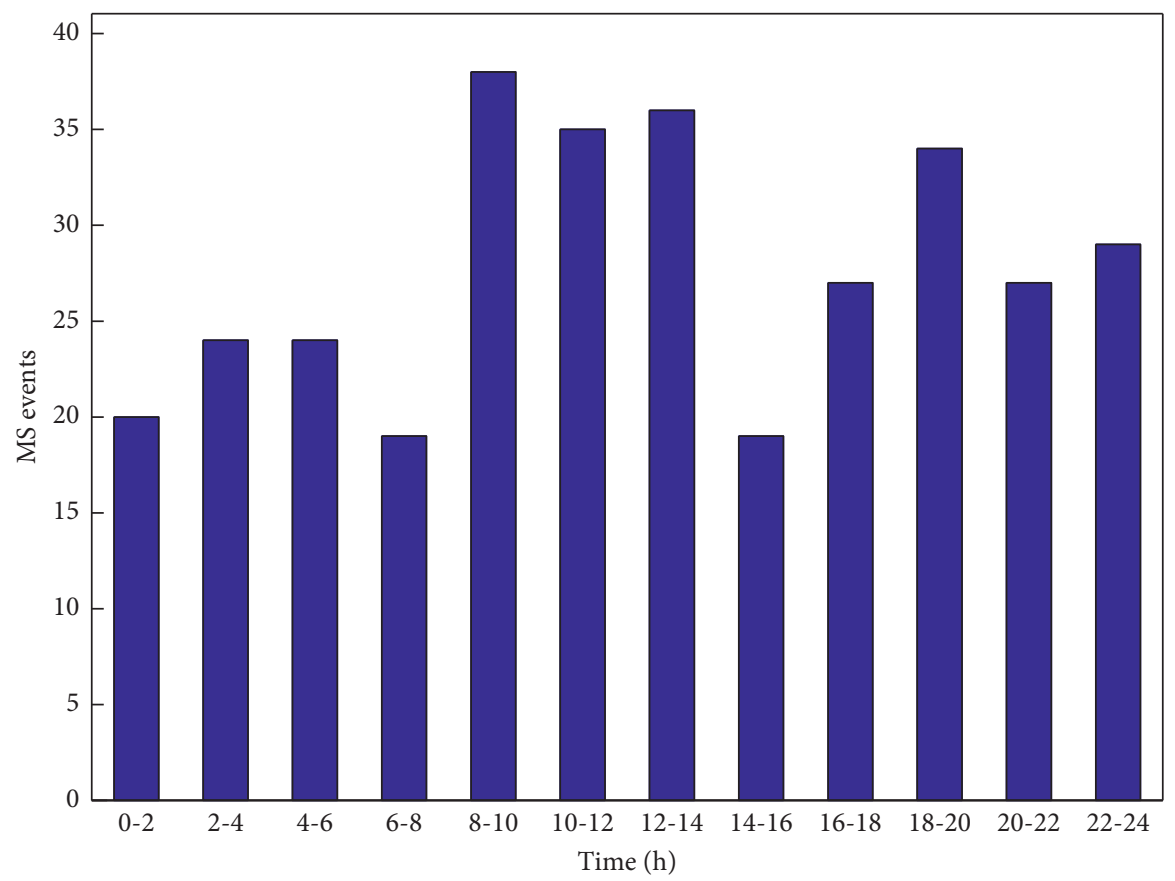

Figure 11: Temporal distribution of the MS events.

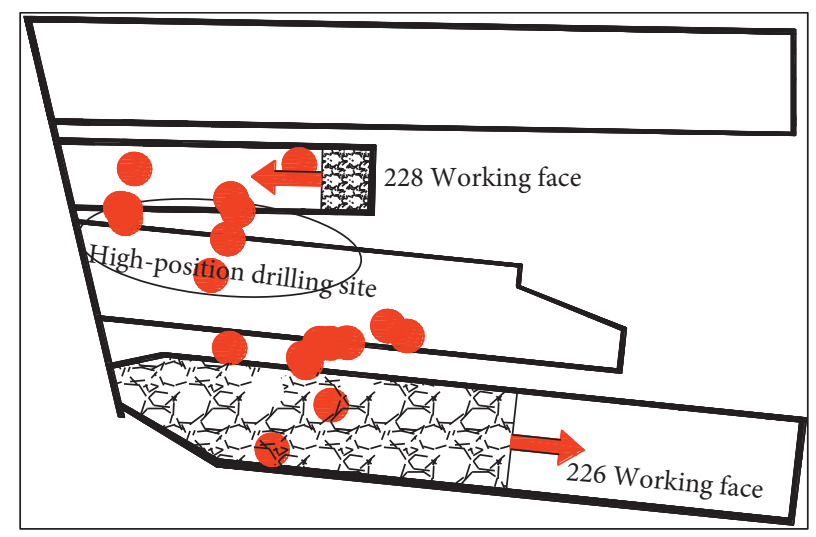

(a)

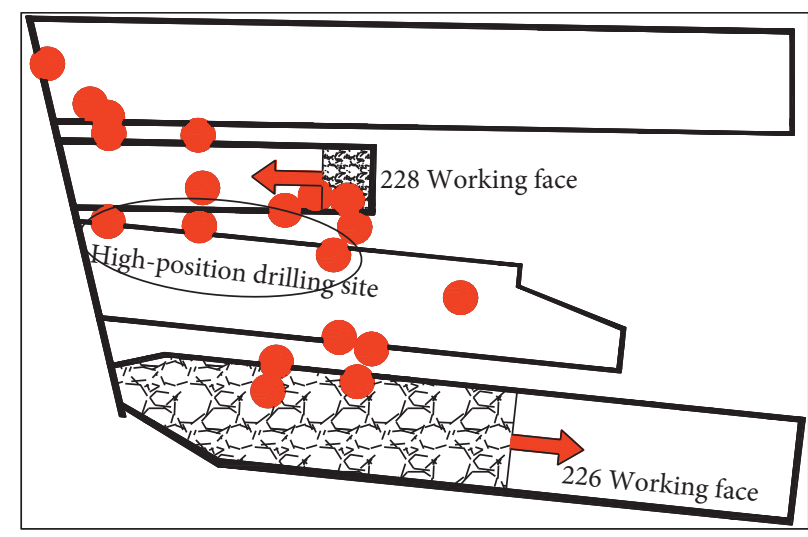

(b)

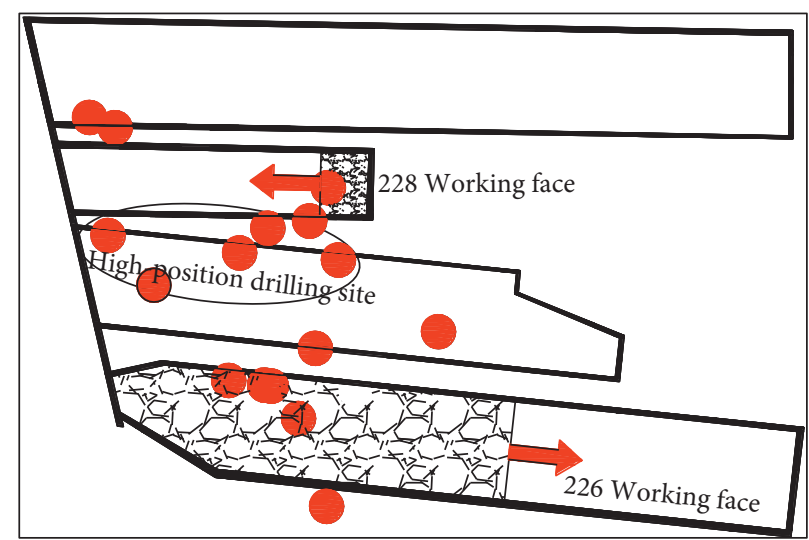

(c)

FIGURE 12: Spatial distribution of the MS events around II228 working face. (a) May 3, 2011; (b) May 11, 2011 ; (c) May $18,2011$. 
TABle 4: The weighting criterion of each support.

\begin{tabular}{lccc}
\hline \multirow{2}{*}{ No. } & \multicolumn{3}{c}{ End-cycle support resistance $(\mathrm{MPa})$} \\
& $\bar{P}_{t}$ & $\sigma_{p}$ & $P_{t i}$ \\
\hline $3 \#$ & 26.4 & 9.3 & 35.7 \\
$6 \#$ & 27.7 & 9.3 & 37 \\
$8 \#$ & 35 & 2.3 & 37.3 \\
$9 \#$ & 34.8 & 2.4 & 37.2 \\
$13 \#$ & 25.7 & 9.4 & 35.1 \\
$14 \#$ & 29.5 & 5.7 & 35.2 \\
\hline
\end{tabular}

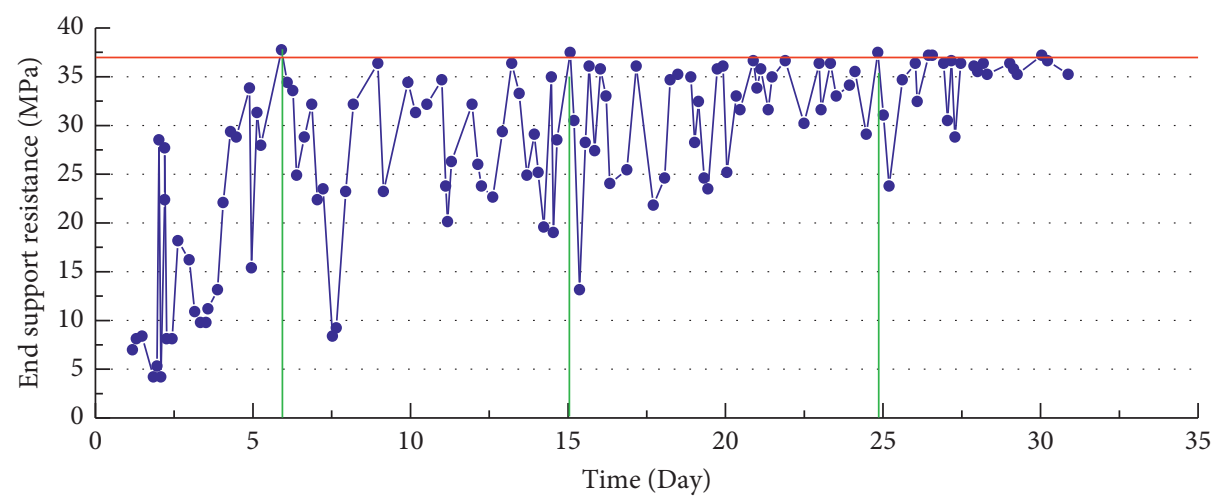

(a)

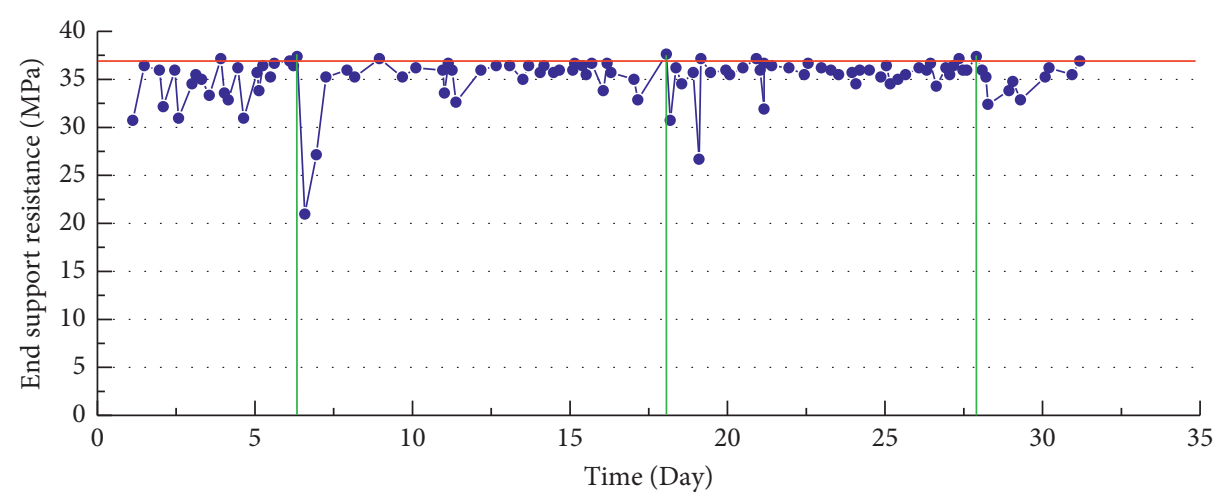

(b)

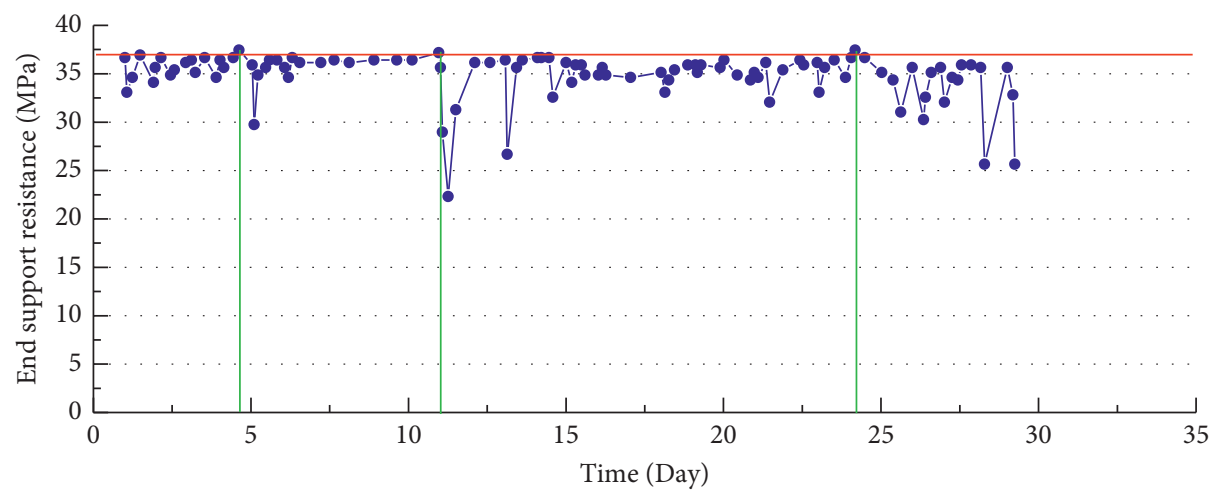

(c)

FIgURE 13: Continued. 


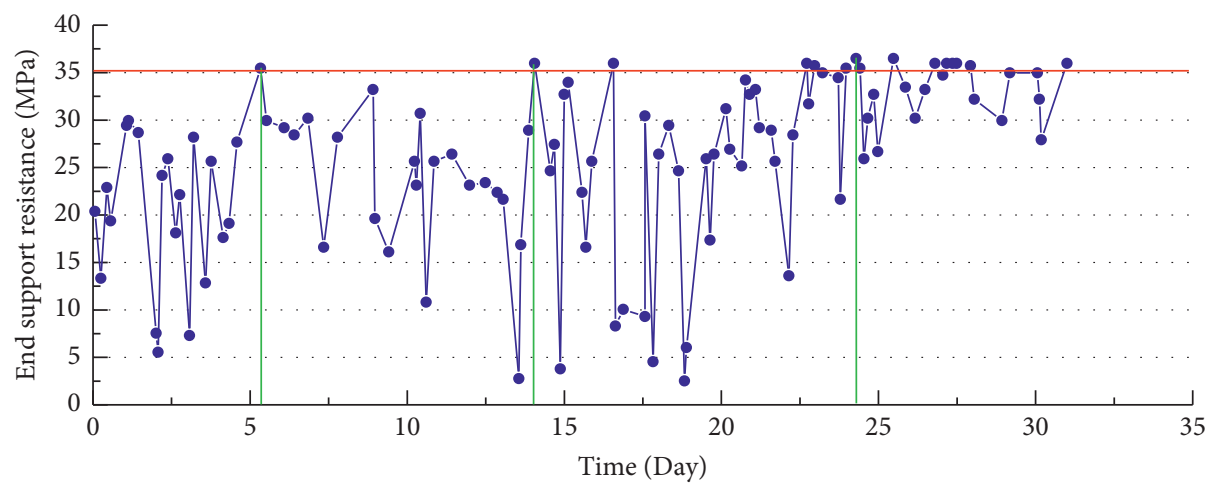

(d)

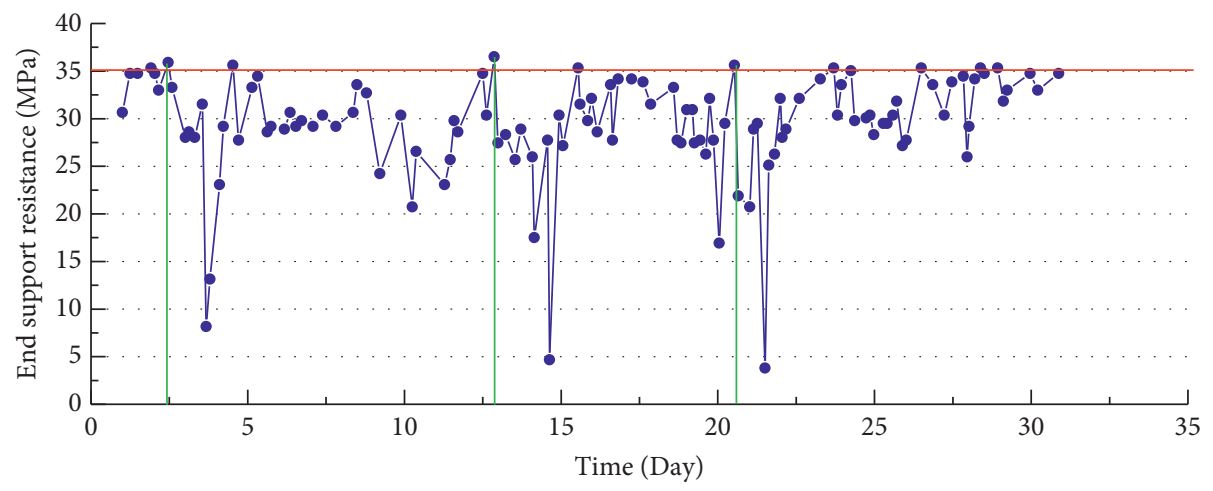

(e)

Figure 13: Variation characteristics of periodic end-cycle support resistance of each support. (a) 6\# hydraulic support. (b) 8\# hydraulic support. (c) 9\# hydraulic support. (d) 13\# hydraulic support. (e) 14\# hydraulic support.

TABLE 5: The statistics of periodic weighting time of each support in June.

\begin{tabular}{lccc}
\hline No. & Fist weighting & Second weighting & Third weighting \\
\hline $3 \#$ & 3rd June & 14th June & 22th June \\
$6 \#$ & 5th June & 15th June & 24th June \\
$8 \#$ & 6th June & 18th June & 18th June \\
$9 \#$ & 4th June & 10th June & 24th June \\
$13 \#$ & 6th June & 14th June & 24th June \\
$14 \#$ & 2nd June & 12th June & 19th June \\
\hline
\end{tabular}

frequency and energy can be precursor information for roof pressure. With the advancement of the working face, the MS energy has the characteristic of periodic distribution, which is consistent with the periodic weighting revealed by the working resistance of the support.

\section{Discussion}

In the process of fracturing and sliding of coal and rock under the mining disturbances, microseismic waves with a certain frequency will propagate to the surrounding rock, which is also accompanied by the release of accumulated energy. The amplitude and frequency of the waves depend on the strength, stress state, fracture size, and the deformation speed of coal and rock [35]. The incubation process of rock burst is actually the process of the occurrence and expansion of cracks or secondary cracks in coal and rock mass structure, which is the process of energy accumulation. And the occurrence of rock burst is the fracture and instability process of damage rock structure, which is the process of energy release [36]. The vibration energy of the roof pressure signals is large, and the amplitude of the signal is about $10^{4}$, which is due to the large deformation and failure area in the rock mass during the roof rupturing, and a large amount of elastic energy is released. Actually, for the process of fault activation, the initial instability of surrounding rock compaction fault is the initial stage of fault activation, and the single vibration energy generated is large, but the frequency is low. Then, the elastic stick-slip oscillation process of surrounding rock is the most important stage of the release of fault activation energy, and the vibration frequency is high. And the vibration frequency and energy are low in the process of plastic stick-slip failure. With the vibration energy and frequency of the surrounding rock in the stage of restabilization of the failure of the wall rock, the release of energy is large [37]. It can be seen that the analysis results of this paper are consistent with previous studies. Besides, the energy accumulated in coal and rock mass increases gradually, and the energy is in a stable release state. When the propulsion speed reaches a certain degree, this stable state will be destroyed, and the sudden release of energy will lead to the occurrence of large energy events. Thus, the distribution characteristic of MS energy and events can reflect the roof movement. 


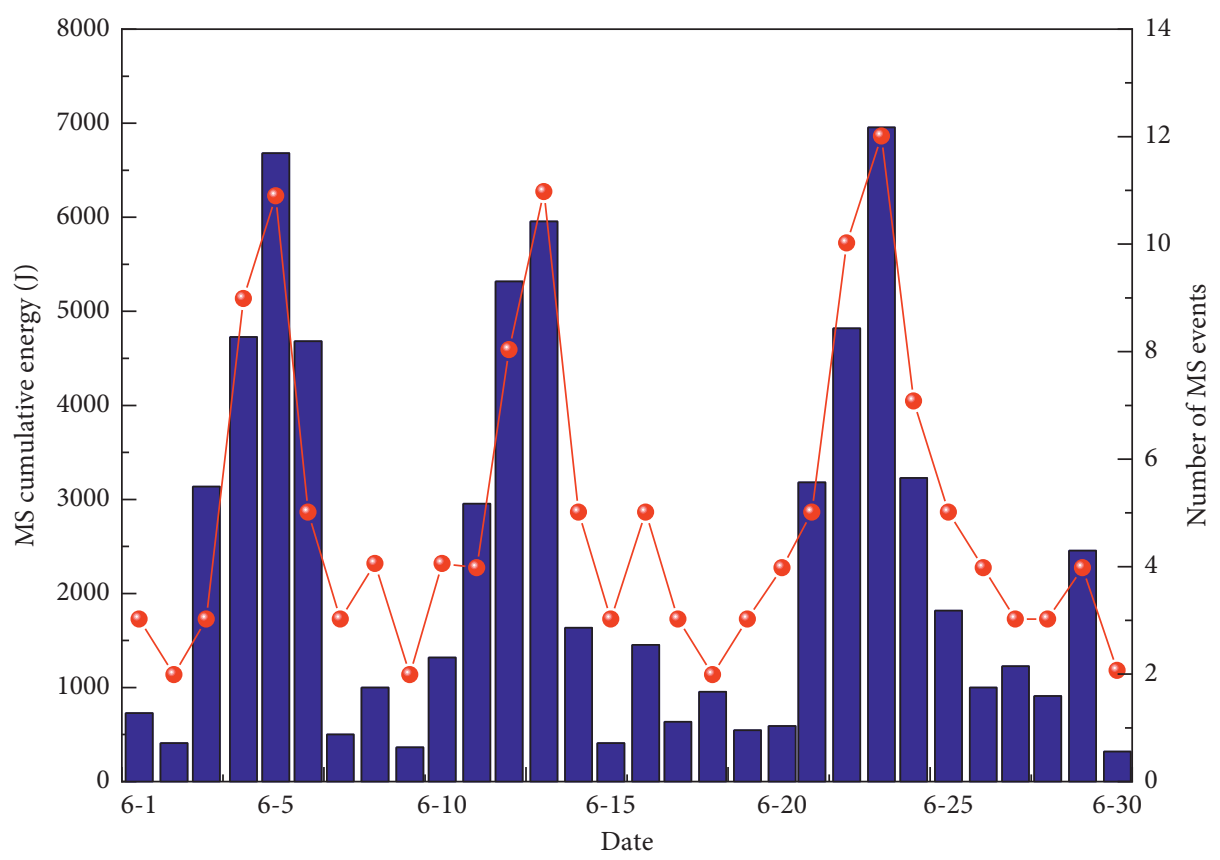

FIGURE 14: The daily number and total energy of MS events before and after three periodic weighting times in June.

\section{Conclusion}

(1) There are large differences in the waveform and spectral characteristics of MS signals at different energy levels. High-level energy seismic signals are characterized by large amplitudes, low frequencies, relatively concentrated distribution, long vibration duration, and slow attenuation. As the energy decreases, the vibration attenuation rate gradually becomes faster, and the signal duration becomes shorter. Besides, the dominant frequency gradually develops from concentration to diffusion.

(2) Due to the different fracture mechanisms of rock or coal mass, the different types of vibration induced by underground mining activities are different. There is a strong impact risk during fault activation because of its more released energy. In comparison, less energy would be released during roof falling.

(3) With the advancement of the working face, the MS energy has the characteristic of periodic distribution, which is consistent with the periodic weighting revealed by the working resistance of the support. 1-2 days before the periodic weighting of working face, the MS events would increase. Combined with the real-time monitoring of hydraulic support, these MS characteristics can be regarded as precursory information of periodic weighting.

\section{Data Availability}

The data reported in this article are available from the corresponding author upon request.

\section{Disclosure}

Meanwhile, the sponsors had no role in the design of the study; in the collection, analyses, or interpretation of data; in the writing of the manuscript; and in the decision to publish the results.

\section{Conflicts of Interest}

The authors declare no conflicts of interest, and the manuscript is approved by all authors for publication.

\section{Acknowledgments}

This work was financially supported by Liaoning Revitalization Talents Program (Grant no. XLYC 1907168) and Natural Science Foundation of Liaoning Province (2019MS-163).

\section{References}

[1] M. Tutak, J. Brodny, D. Szurgacz, L. Sobik, and S. Zhironkin, "The impact of the ventilation system on the methane release hazard and spontaneous combustion of coal in the area of exploitation-a case study," Energies, vol. 13, no. 18, Article ID 4891, 2020.

[2] B. Zhou, J. Xu, S. Peng et al., "Effects of geo-stress on the dynamic response of multi-physical field parameters during coal and gas outbursts under true triaxial stress," International Journal of Rock Mechanics and Mining Sciences, vol. 142, Article ID 104759, 2021.

[3] J. Lu, C. Jiang, Z. Jin, W. Wang, W. Zhuang, and H. Yu, "Three-dimensional physical model experiment of mininginduced deformation and failure characteristics of roof and floor in deep underground coal seams," Process Safety and Environmental Protection, vol. 150, pp. 400-415, 2021. 
[4] X. Li, S. Chen, E. Wang, and Z. Li, "Rockburst mechanism in coal rock with structural surface and the microseismic (MS) and electromagnetic radiation (EMR) response," Engineering Failure Analysis, vol. 124, Article ID 105396, 2021.

[5] R. Jiang, F. Dai, Y. Liu, and A. Li, "A novel method for automatic identifcation of rock fracture signals in microseismic monitoring," Measurement, vol. 175, Article ID 109129, 2021.

[6] Y. Zhao, C. Cheng, Y. Liu, and G. Jing, "Study on microseismic and charge induction signal characteristics of different types of rock loading failure," Journal of Water Resources \& Water Engineering, vol. 30, no. 5, pp. 199-203, 2021.

[7] W. Zhang, T. Huo, C. Li, C. Wang, X. Qu, and C. Xin, "Characteristics of valuable microseismic events in heading face of an underground coal mine using microseismic system," Shock and Vibration, vol. 2021, Article ID 6683238, 2021.

[8] Y. Zhao, G. Jing, Y. Fan, and Y. Pan, "Experimental study on the microseism and charge signal time-frequency characteristics in the process of fault stick-slip instability," Chinese Journal of Rock Mechanics and Engineering, vol. 39, no. 7, pp. 1385-1395, 2020.

[9] Y. Xiao and X. Li, "Evolution of microseismic main frequency during intensive rockburst development in deep tunnel," Journal of Shandong University of Science and Technology, vol. 39, no. 4, pp. 14-19, 2020.

[10] H. Wang and Q. Zong, "Study on safety of blasting vibration of super deep hole blasting in coal mine," Journal of Safety and Environment, vol. 15, no. 5, pp. 59-63, 2015.

[11] B. Li, N. Li, E. Wang, X. Li, Y. Niu, and X. Zhang, "Characteristics of coal mining microseismic and blasting signals at Qianqiu coal mine," Environ Earth Sci, vol. 76, Article ID 722, 2017.

[12] X. Zhang, R. Jia, X. Lu, Y. Peng, and W. Zhao, "Identification of blasting vibration and coal-rock fracturing microseismic signals," Applied Geophysics, vol. 15, no. 5, pp. 280-289, 2018.

[13] J. Li, W. Lei, H. Zhao, T. Wang, Y. Liu, and H. Zhang, "Microseismic characteristics during impact failure of coal and rock under repetitive blast mining," Journal of China University of Mining \& Technology, vol. 48, no. 5, pp. 966-974, 2018.

[14] C. Zhang, G. Jin, C. Liu et al., "Prediction of rockbursts in a typical island working face of a coal mine through microseismic monitoring technology," Tunnelling and Underground Space Technology, vol. 113, Article ID 103972, 2021.

[15] Z. Liang, R. Xue, N. Xu, and W. Li, "Characterizing rockbursts and analysis on frequency-spectrum evolutionary law of rockburst precursor based on microseismic monitoring," Tunnelling and Underground Space Technology, vol. 105, Article ID 103564, 2020.

[16] Y. Wang, D. Lei, Y. Zheng, and T. Ma, "Study on response characteristics of surrounding rock rupture microseismic events during coal roadway excavation," Tunnelling and Underground Space Technology, vol. 2021, Article ID 9955994, 2021.

[17] Y. Zhao, Y. Jiang, T. Wang, F. Gao, and S. Xie, "Features of microseismic events and precursors of rock burst in underground coal mining with hard roof," Journal of China Coal Society, vol. 37, no. 12, pp. 1960-1967, 2012.

[18] P. Jiang, F. Dai, N. Xu, T. Li, and B. Li, “Analysis of correlation between fracture scale and frequency characteristic of rock mass and its engineering verification," Rock and Soil Mechanics, vol. 37, no. s2, pp. 483-492, 2016.

[19] Z. Tang, X. Liu, Q. Xu, C. Li, and P. Qin, "Stability evaluation of deep-buried TBM construction tunnel based on microseismic monitoring technology," Tunnelling and Underground Space Technology, vol. 81, pp. 512-524, 2018.

[20] Q. Qi and L. Dou, Rock Burst Theory and Technology, China University of Mining and Technology press, Xuzhou, China, 2008.

[21] C. Liu, S. Li, C. Cheng, and X. Cheng, "Identification methods for anomalous stress region in coal roadways based on microseismic information and numerical simulation," International Journal of Mining Science and Technology, vol. 27, no. 3, pp. 525-530, 2017.

[22] M. Ge, "Efficient mine microseismic monitoring," International Journal of Coal Geology, vol. 64, no. 1-2, pp. 44-56, 2005.

[23] X. Li, Z. Li, E. Wang et al., "Analysis of natural mineral earthquake and blast based on Hilbert-Huang transform (HHT)," Journal of Applied Geophysics, vol. 128, pp. 79-86, 2016.

[24] Y. Fujii and K. Sato, "Difference in seismic moment tensors between microseismic events associated with a gas outburst and those induced by longwall mining activity: proc 2nd International Symposium on Rockbursts and Seismicity in Mines, Minneapolis, 8-10 June 1988 P71-75. Publ Rotterdam: a A Balkema, 1990," International Journal of Rock Mechanics and Mining Science \& Geomechanics Abstracts, vol. 28, no. 6, Article ID A397, 1991.

[25] X. Luo, P. Hatherly, and M. Gladwin, "Application of microseismic monitoring to longwall geomechanics and safety in Australia," in Proceedings of the 17th International Conference on Ground Control in Mining, pp. 72-78, Morgantown, WV, USA, August 1988.

[26] J. Liu, S. Xu, and Y. Li, "Analysis of rock mass stability according to power-law attenuation characteristics of acoustic emission and microseismic activities," Tunnelling and Underground Space Technology, vol. 83, pp. 303-312, 2019.

[27] G. Wang, S. Gong, L. Dou, H. Wang, W. Cai, and A. Cao, "Rockburst characteristics in syncline regions and microseismic precursors based on energy density clouds," Tunnelling and Underground Space Technology, vol. 81, pp. 83-93, 2018.

[28] F. Essrich, "Quantitative rockburst hazard assessment at Elandsrand gold mine," Journal of the South African Institute of Mining and Metallurgy, vol. 97, no. 7, pp. 319-324, 1997.

[29] T. H. Ma, C. A. Tang, L. X. Tang, W. D. Zhang, and L. Wang, "Rockburst characteristics and microseismic monitoring of deep-buried tunnels for Jinping II hydropower station," Tunnelling and Underground Space Technology, vol. 49, pp. 345-368, 2015.

[30] S. Zhu, Y. Feng, F. Jiang, and J. Liu, "Mechanism and risk assessment of overall-instability-induced rockbursts in deep island longwall panels," International Journal of Rock Mechanics and Mining Sciences, vol. 106, pp. 342-349, 2018.

[31] X. Chen, W. Li, and X. Yan, "Analysis on rock burst danger when fully-mechanized caving coal face passed fault with deep mining," Safety Science, vol. 50, no. 4, pp. 645-648, 2012.

[32] C.-P. Lu, L.-M. Dou, N. Zhang et al., "Microseismic frequency-spectrum evolutionary rule of rockburst triggered by roof fall," International Journal of Rock Mechanics and Mining Sciences, vol. 64, pp. 6-16, 2013.

[33] A. Sainoki and H. S. Mitri, "Effect of slip-weakening distance on selected seismic source parameters of mining-induced fault-slip," International Journal of Rock Mechanics and Mining Sciences, vol. 73, pp. 115-122, 2015.

[34] Y. Li, G. Lei, S. Xu, and D. Wu, "The spatial-temporal evolution law of microseismic activities in the failure process of 
deep rock masses," Journal of Applied Geophysics, vol. 154, pp. 1-10, 2018.

[35] S. Wang, G. Zhu, K. Zhang, and L. Yang, "Study on characteristics of mining earthquake in multicoal seam mining under thick and hard strata in high position," Shock and Vibration, vol. 2021, Article ID 6675089, 2021.

[36] Y. Zhang, "The different actions to the roof support of trusses and common bolts," Ground Pressure and Strata Control, vol. 16, no. 3/4, pp. 159-161, 1999.

[37] X. Guo, L. Dou, C. Lu, Z. Li, B. Liu, and C. Lv, "Research on the microseismic activity of fault reaction induced by coal mining," Safety In Coal Mines, vol. 42, no. 1, pp. 26-30, 2011. 